\title{
المسائل العقدية المستنبطة من حديث "اللهم وليديه فاغفر" دراسة عقدية
}

\section{بدرية بنت محمد الفوزان}

أستاذ العقيدة- كلية التربية- دراسات إسلامية- جامعة الملك سعود- السعودية balfawzan@ksu.edu.sa

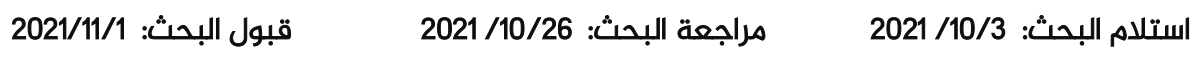

DOI: https://doi.org/10.31559/SIS2021.6.2.5 


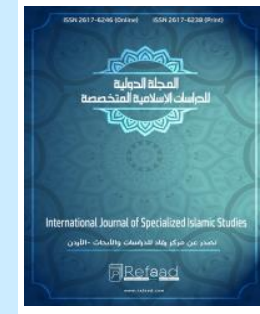

المسـائل العقدية المستنبطة من حديث "اللهم وليديه فاغفر"

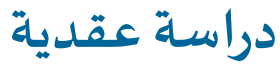 \\ بدرية بنت محممد الفوزان \\ أستاذ العقيدة- كلية التربية- دراسات إسلامية- جامعة الملك سعود- السعودية بلات \\ balfawzan@ksu.edu.sa
}

DOI: https://doi.org/10.31559/SIS2021.6.2.5 2021/10/3 مراجعة البحث: 2021/10/26 قبول البحث: 2021/11/1 البحث

هذا البحث بعنوان" المسائل العقدية في حديث "اللهم وليديه فاغفر" دراسة عقدية

ونص الحديث محل الدراسة فياء عدد من مسائل العقيدة والإيمان التي هي محل رد لمن انحرف من الفرق في مفهوم الإيمان

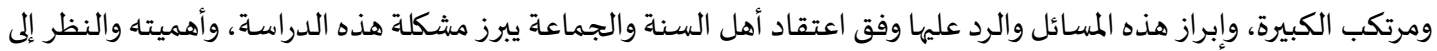

ضوابط الإيمان، والتكفير، ومعالجة بعض الانحرافات في قضية مرتكب الكبيرة، من خلال عقيدة أهل السنة في ذلك ومن خالفها من الفرق من خلال نص الحديث النبوي، وفق منهج تحليلي استدلالي يتمثل في "تحليل واستنباط" لمسائل العقيدة في نص مصني

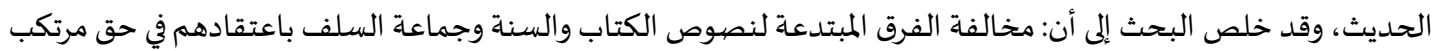
الكبيرة، وفياه دلالة على أن الله لم يحبط عمل من قتل نفساه وهو مؤمن، وهاجر إلى دين الله ونبيه صلى الله عليه وسلم، ولو كان

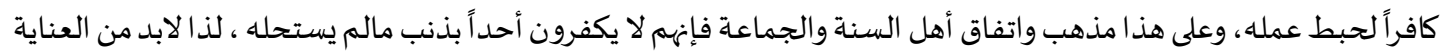

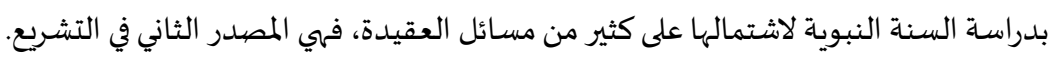
الكلمات المفتاحية: العقيدة؛ مرتكب الكبيرة؛ التكفير؛ الإيمان.

إن الحمد الله نحمده، ونستعينه، ونستغفره، ونعوذ بالله من شرور أنفسنا، ومن سيئات أعمالنا، من يهده الله فلا مضل لله، ومن

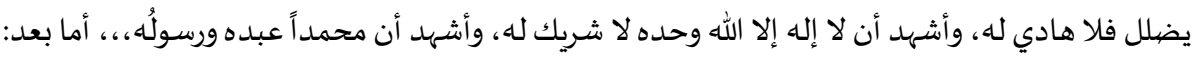
إن الانحراف في فهم حقيقة الإيمان ومسائله، هو أول خلل اعتقادي ظهر في الأمة، فالانحراف والغلو ظهر لدى الخوارج، ثم

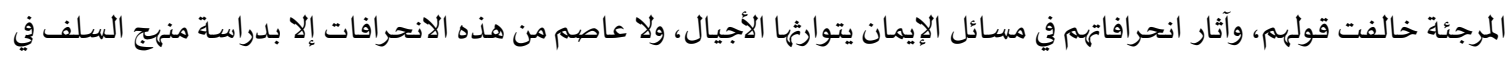
مسائل الإيمان والتكفير، وفق نصوص الكتاب والسنة، وفهم السلف الصالح لها، ومسائل الإسلام والإيمان والكفر والنفاق مسائل

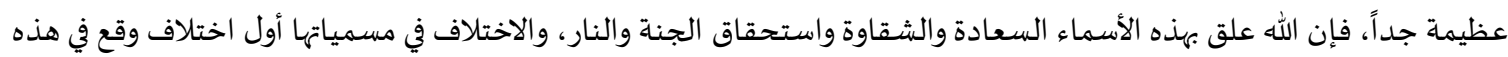

وهذه الدراسـة حديث تبرز أهم مسائل العقيدة المستنبطة من حديث "اللهم وليدياه فاغفر"، والاختلاف الواقع بين الفرق في هذه 


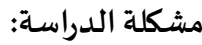

إن الفِرقَ المُنحرفة -كالمرجئة والخوارج والمعتزلة -لما انحرفت العقيدة في قلوبهم عن الكتاب والسنة، اعتقدوا أن الإيمانَ هو المعرفة

في القلب فقط، وأخرجوا العمل من مُسمَّى الإيمان، ومشكلة الدراسة تبرز في عدد من الأسئلة في هذا الحديث النبوي:

1. ـ هل صاحب الكبيرة يخرج من الملة بكبيرته

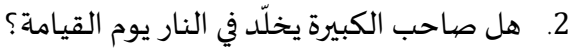

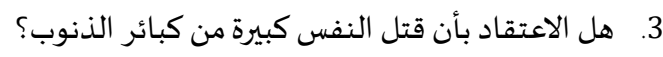

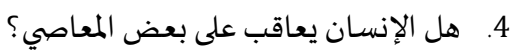

5. ما أهمية الرؤى في الإسلام؟ وهل تكون سببًا لثبوت بعض الأحكام الشرعية؟

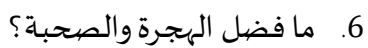

أهمية الدراسـة:

1. بيان أهمية النظر إلى ضيوابط الإيمان، والتكفير، لكي يتضح دقة أهل السنة والجماعاة في مواقفهم وأحكامههم.

2. معالجة بعض الانحرافات في قضية مرتكب الكبيرة، وإبراز عقيدة أهل السنة في ذلك ومن خالفها من الفرق.

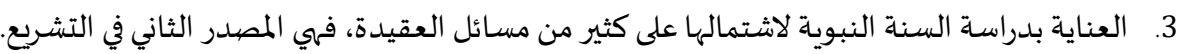

4. اشتمال الحديث محل الدراسة على عدد من المسائل العقدية الهامة والتي خالفت فيها بعض الفرق الإسلامية منهج السلف.

أهداف الدراسـة: - (ماف:

1.

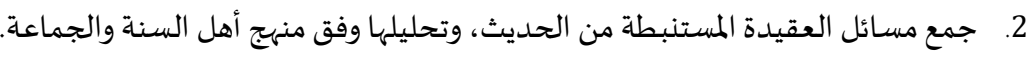

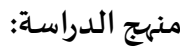

ستكون الدراسـة وفق منهج تحليلي استنباطي، وكانت الأداة محتوى الأدلة ذات العلاقة والصلة بالموضوع، من خلال كتب العقيدة أو الفرق وأقوال العلماء في ذلك للوصول لهدف الدراسـة.

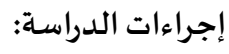

وتتمثل في:

1 1 تحليل واستنباط مسائل العقيدة في نص الحديث.

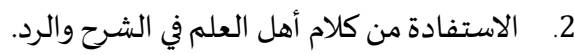

3. - العناية بصحة الدليل والاستدلال.

4. توثيق النصوص والاعتماد على المصادر الأصلية، مع ذكر بيانات الكتاب عند ورودها أول مرة.

$$
\text { 5. ت تخريج الأحاديث والآيات. }
$$

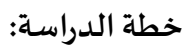

قمت بتقسيم البحث إلى مقدمة ومبحثين:

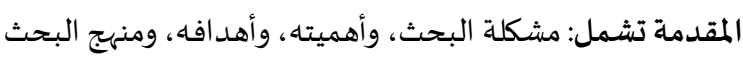

المبحث الأول: التعريف بحديث " اللهم وليديه فاغفر" وراويه

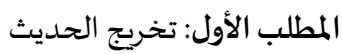

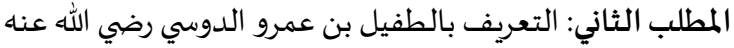

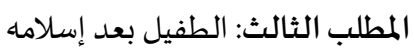

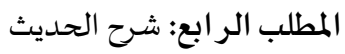

المبحث الثاني: دراسـة مسائل العقيدة المستنبطة من الحديث في ضهوء عقيدة أهل السـنة والجماعة

المطلب الأول: صاحب الكبيرة لا يخرج من الملة بكبيرته.

المطلب الثاني: أن صاحب الكبيرة لا يخلّد في النار يوم القيامة.

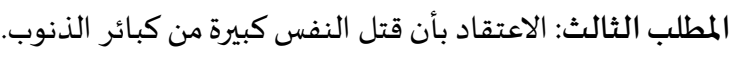

المطلب الر ابع: إثبات عقوبة بعض أصحاب المعاصي. 
المطلب الخامس: الاعتقاد بشفاعة النبي في أهل الكبائر.

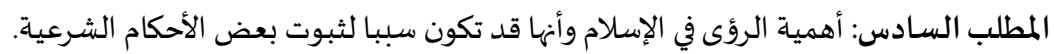

المطلب السابع: الاعتقاد بفضل الهجرة والصحبة.

الخاتمة والنتائج

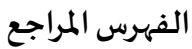

\section{المبحث الأول: التعريف بحديث " اللهم وليديه فاغفر" وراويه}

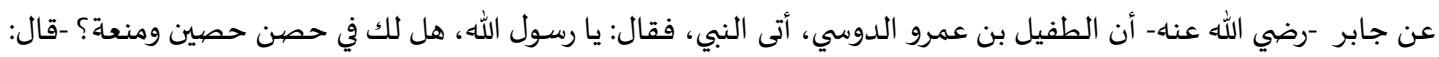

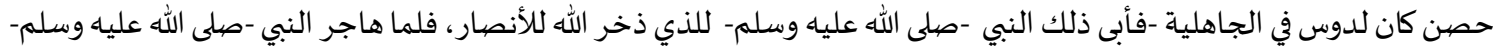

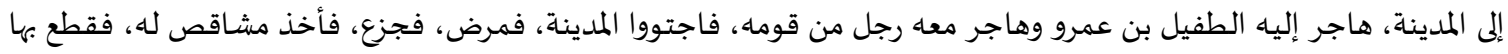

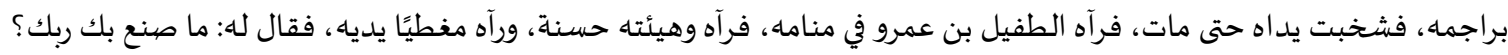

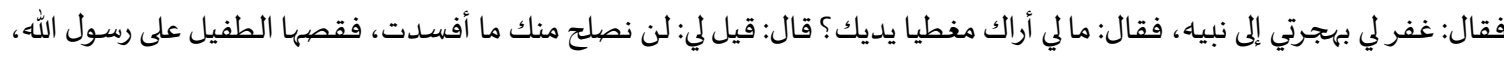

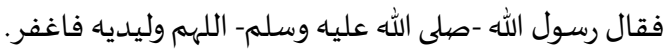

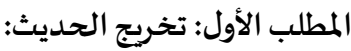

أخرجه الإمام أحمد بن حنبل في مسنده، باقي مسند المكثرين، مسند جابر بن الإبن عبداله الله حديث رقم 1564، الأحاديث مذيلة بأحكام

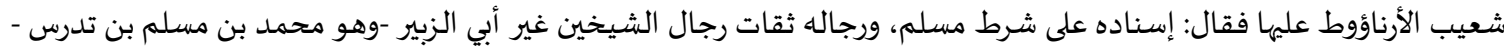

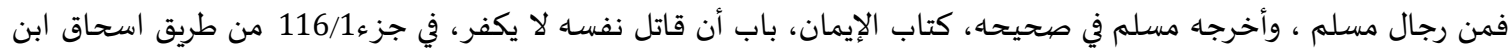

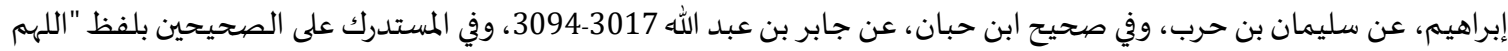

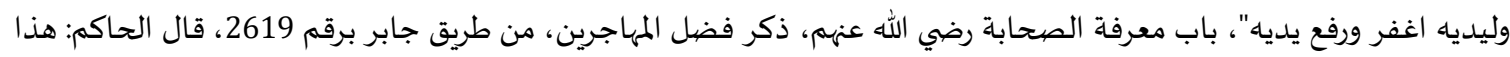

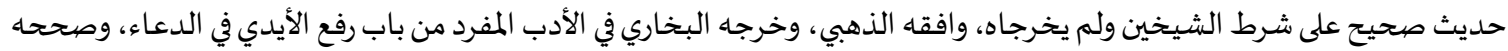

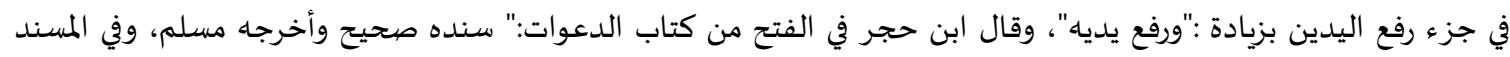

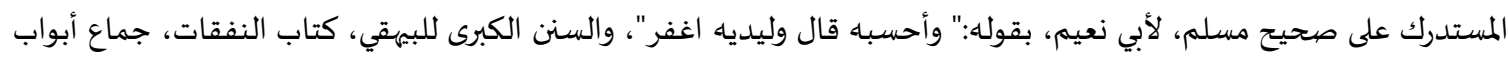

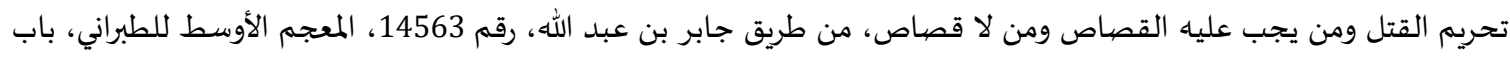

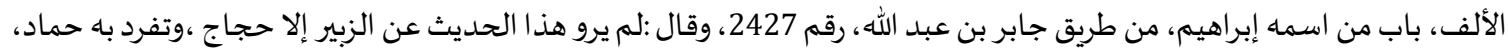

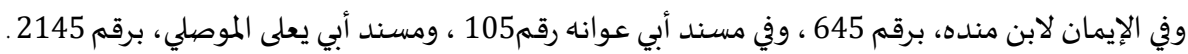
المطلب الثاني: التعريف بالطفيل بن عمرو الدوسي رضي الله عنه: نسببه:

الطفيل بن عمرو بن طريف بن العاص بن ثعلبة بن سليم بن فهم بن غنم بن دوس الدوسي وقيل هو ابن عبد عمرو بن عبد الله

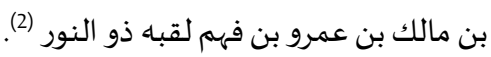

إسلامه (3)

كان رسول الله -صلى الله عليه وسلم- على ما يرى من قومه يبذل لهم النصيحة ويدعوهم إلى النجاة مما هم فيه وجعلت قريش

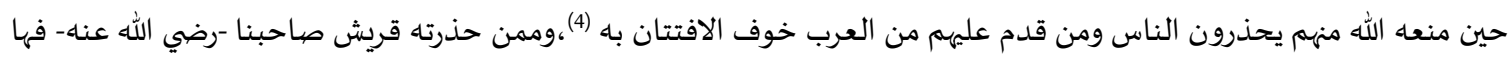

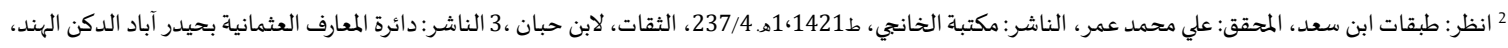

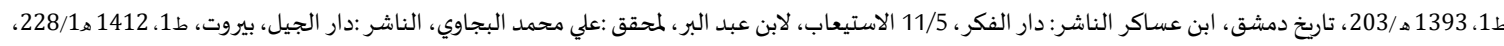

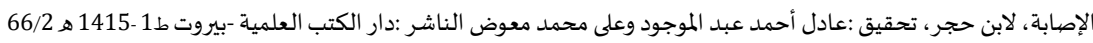

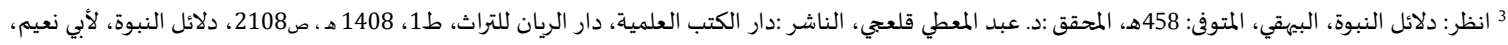

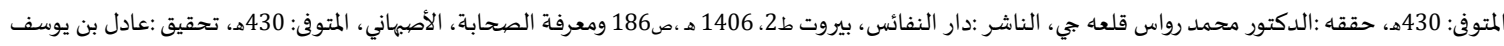

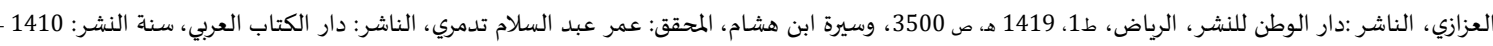
382/19901

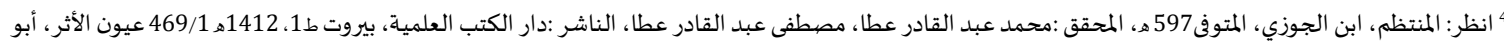

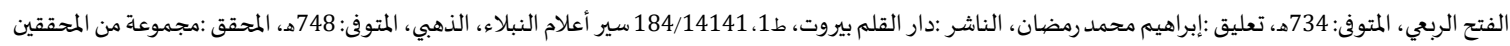

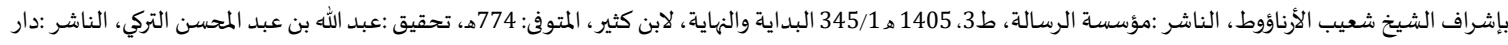

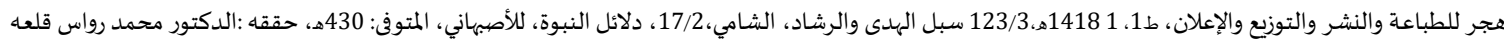

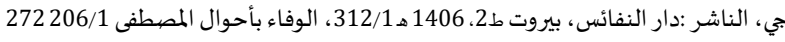




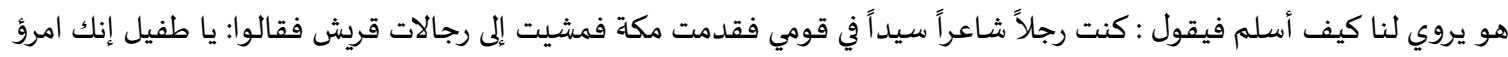

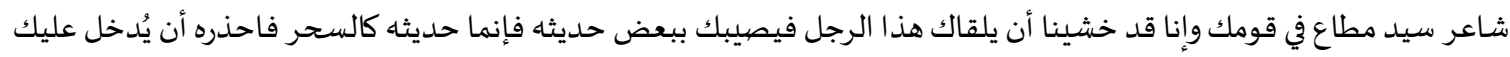

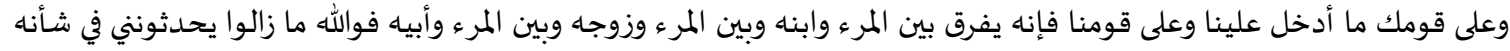

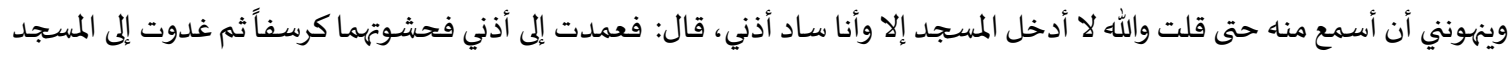

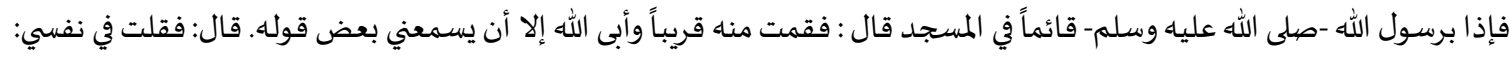

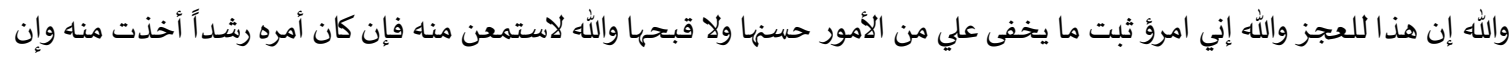

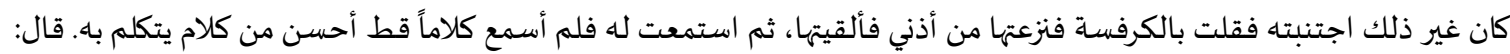

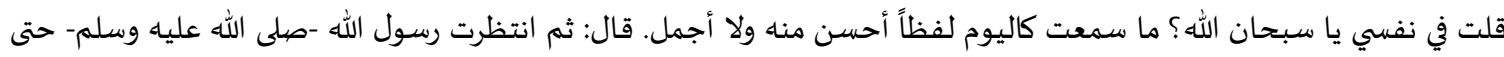

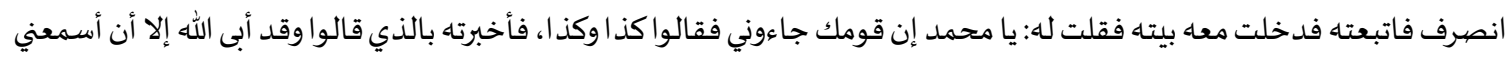

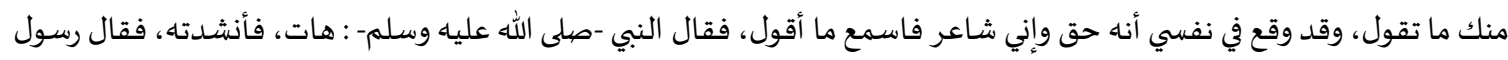

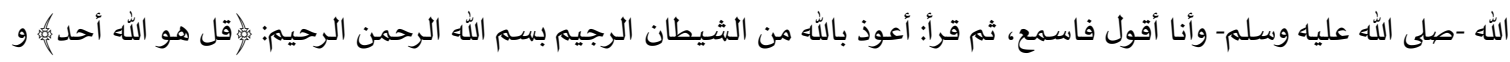

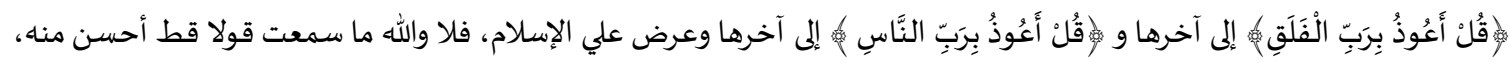

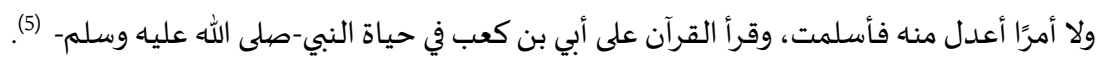

المطلب الثالث: الطفيل بعد إسلامه: بعد إسلامه بلغ ذلك قريشًا فهددوه وتوعدوه وذكَّرهم بأنها سيد دوس وأههم لو تعرضوا له فلن تتركهم دوس فهابوه فقال -رضي

$$
\begin{aligned}
& \text { ألا أبلغ لديك بني لؤي ** على الشنآن والعضب المرد } \\
& \text { بأن الله رب الناس فرد ** تعالى جده عن كل ند (6) لمان المان }
\end{aligned}
$$

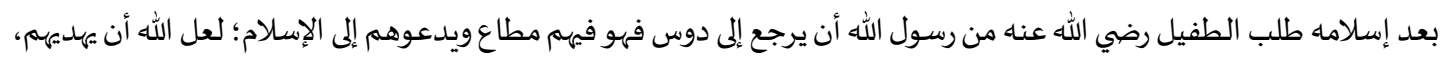

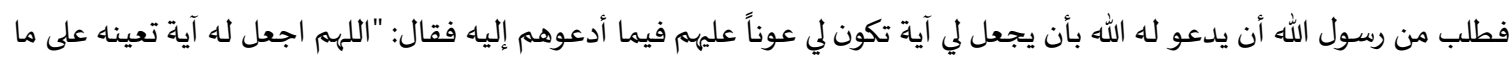

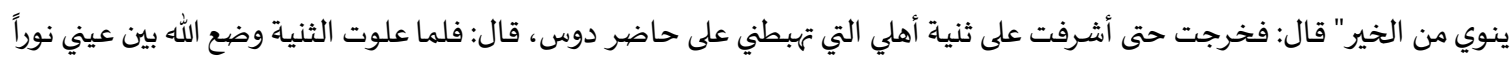

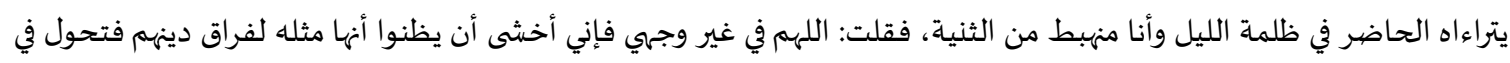

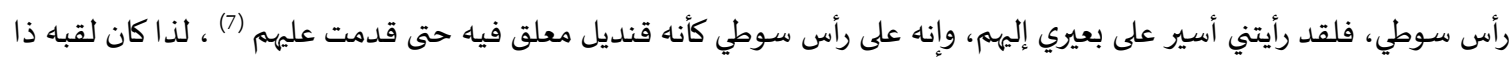

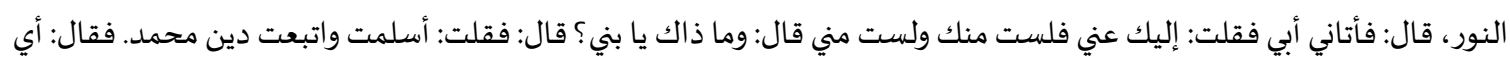

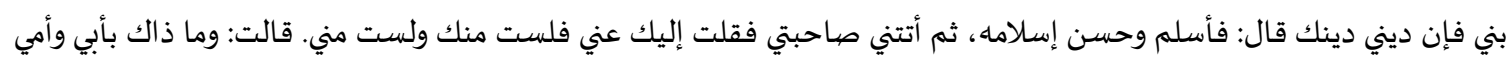

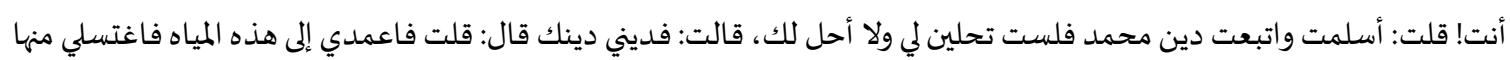

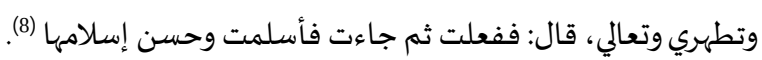

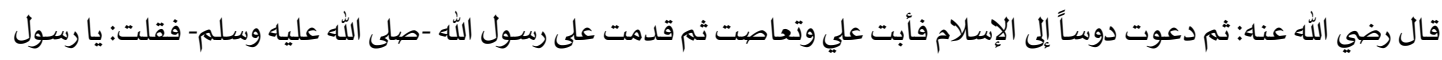

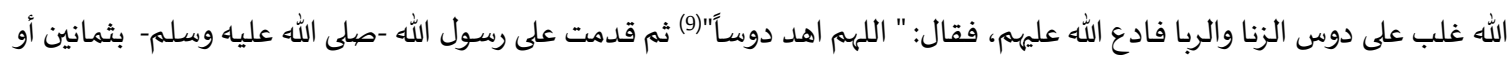

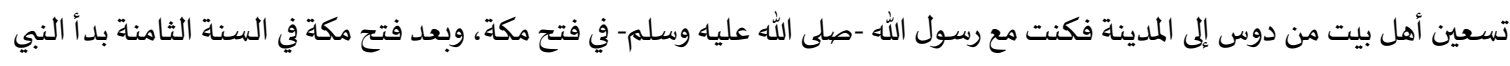

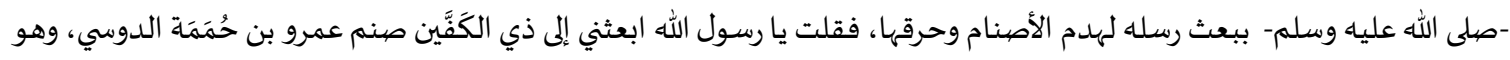

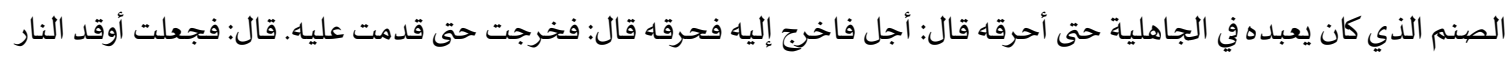

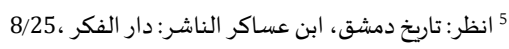

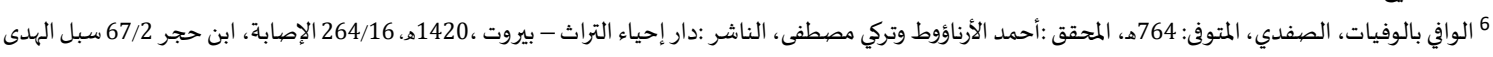

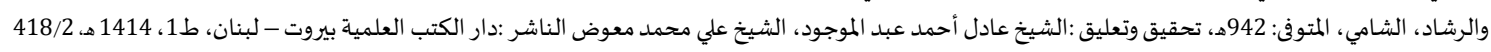

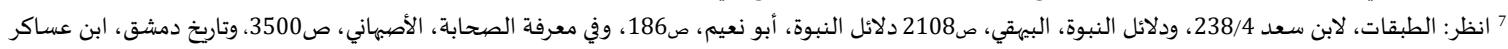


وهو يشتعل بالنار واسماه ذو الكفين وأنا أقول : يا ذا الكَفَّنَ لست من عِبَادِكا * * إني حشوت النار في فؤادك. (10)

وفاته:

لما توفي النبي -صلى الله عليه وسلم- وارتد مَن ارتد مِن العرب عن دين الله تعالى واتفاق الصحابة على قتال المرتدين، بدأ أمير

المؤمنين أبو بكر رضي الله عنه ببعث الجيوش لقتالهم كان الطفيل رضي الله عناه ممن ذهب لقتال مسيلمة الكذاب، وخرج معاه ابنه

عمرو، واستشهد في حروب الردة. (11) بندين

المطلب الر ابع: شرح الحديث:

هل لك في حصن حصين ومنعة: هي بفتح الميم وبفتح النون وإسكانها، لغتان ذكرهما ابن السكيت والجوهري وغيرهما، والفتح أفصح،

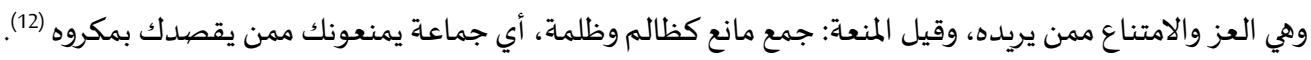

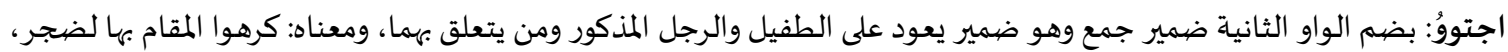

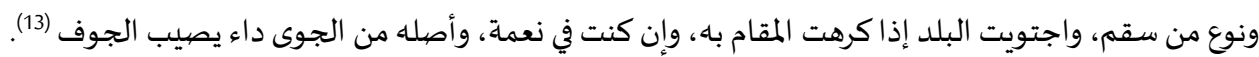

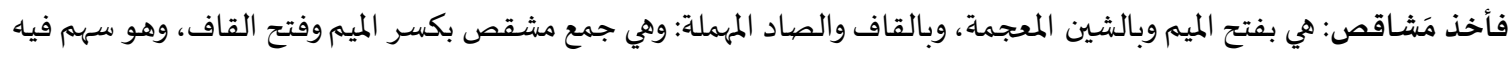

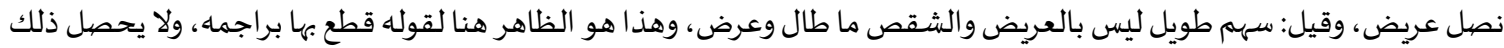

إلا بالعريض. (14) والبراجم: بفتح الباء الموحدة وبالجيم فهي: مفاصل، وحدتها: برجماة، وقوله: فشخبت يداه: بفتح الشين والخاء المعجمتين أي سال

دمهما، وقيل: سال بقوة.

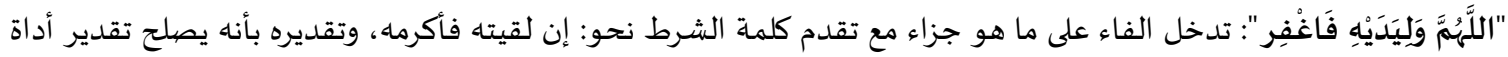

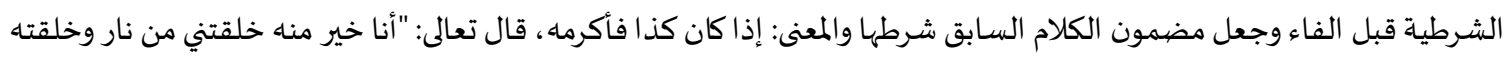
من طين قال فاخرج " أي: إذا كان عندك هذا الكبر فاخرج، ومن هنا فهذا الحديث تقديره: اللهم إن كنت غفرت لسائر أعضائر أعضائه فاغفر

ليديه (16)، وقيل: الواو عاطفة على محذوف والتقائ إذاندير اللهم غفرت لله وليديا فاغفر ، أي كما غفرت لبقية بدناه فاغفر ليديه. (17)

\section{المبحث الثاني: دراسة مسائل العقيدة المستنبطة من الحديث في ضوء عقيدة أهل السنة والجماعة}

المطلب الأول: صاحب الكبيرة لا يخرج من الملة بكبيرته:

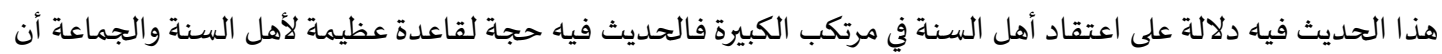

من قتل نفسـه أو ارتكب معصية وغيرها ومات من غير توبة فليس بكافر ، ولا يقطع له بالنار، بل هو في حكم المشيئة لله عزوجل. (18)

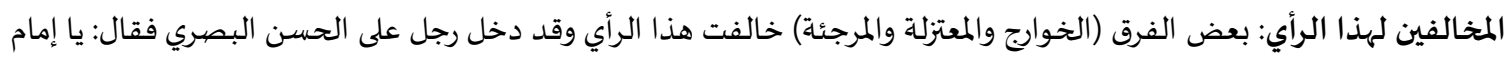

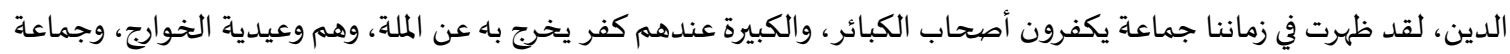

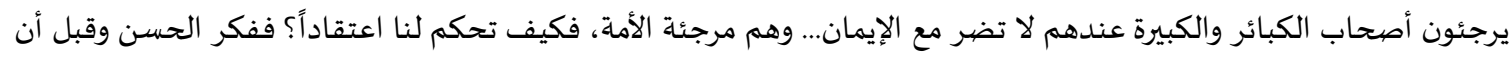

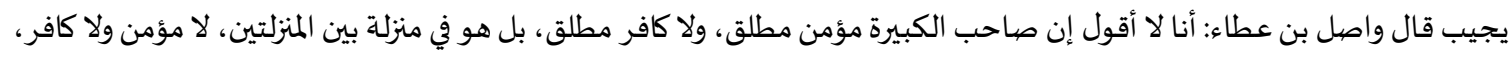
ثم قام واعتزل في ناحية من المسجد يقرر ما أجاب باه على جماعاة من أصحاب الحسن، ويدعو لهذا الاعتقاد، فقال الحسن: اعتزلنا واصل، فسموا من ذلك الحين بالمعتزلة. (19)

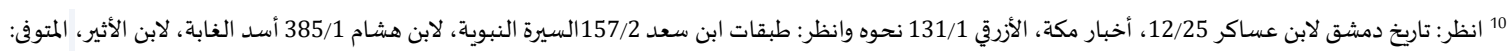

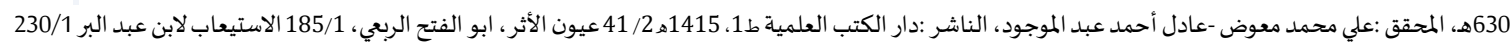

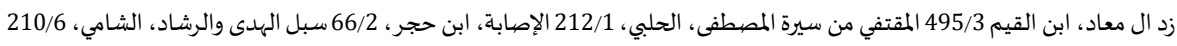

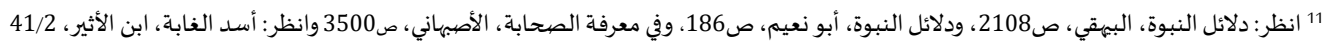

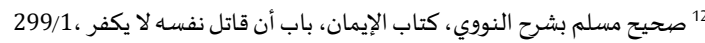

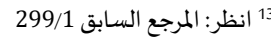

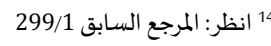
15 16 انظر: عقود الزبرجد في إعراب الحدايث المراب النبوي، لجلال الدين السيوطي، تحقيق حسن موسى الشاعر، عبد الرحمن بن أبي بكر، جلال الدين السيوطي، المتوفى: 911هـ،

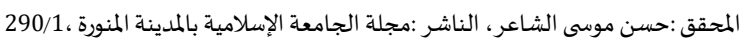

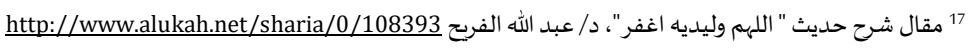
18 19 انظر: الملل والنحل، الشهرستاني، المتوفى: 548ه، الناشر :مؤسسة الحلبي 60/6، والفرق بين الفرق، البغدادي، المتوفى: 429ه، الناشر :دار الآفاق الجديدة، بيروت، ط21977،2، 


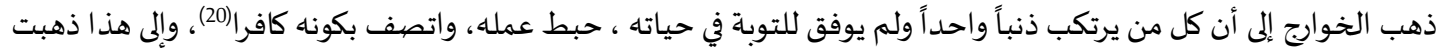

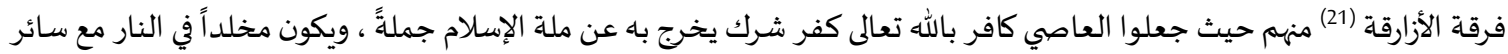

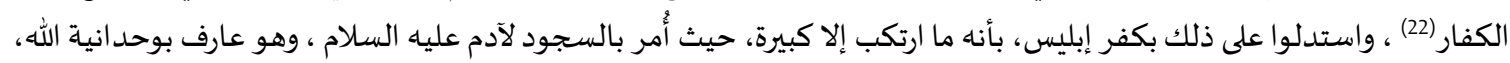

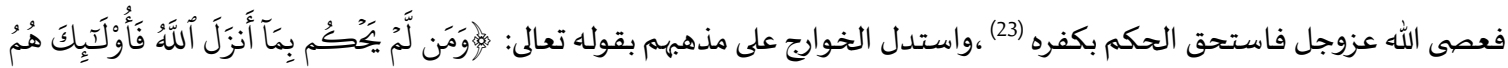

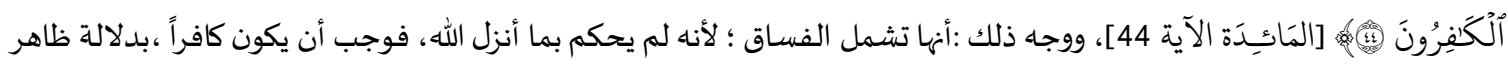

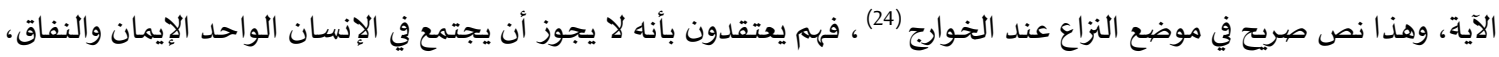

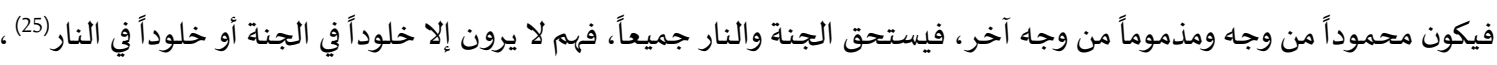

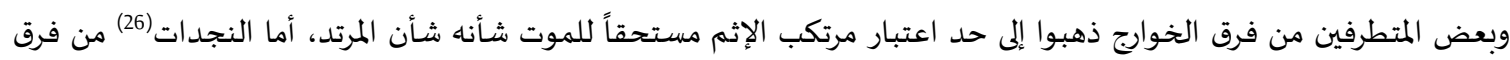

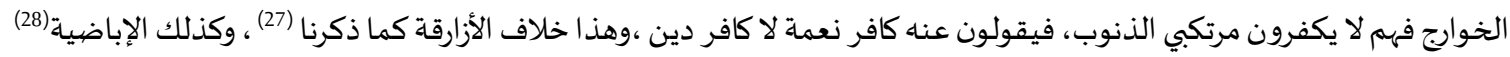

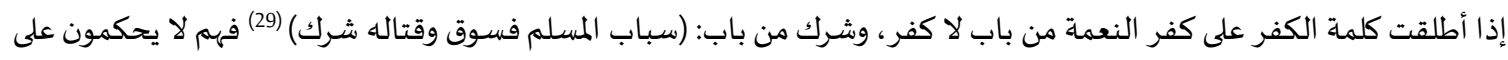

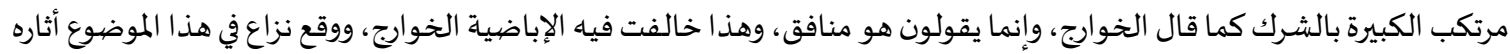

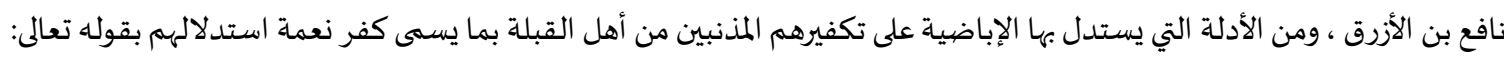

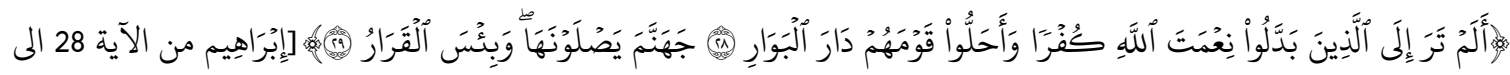

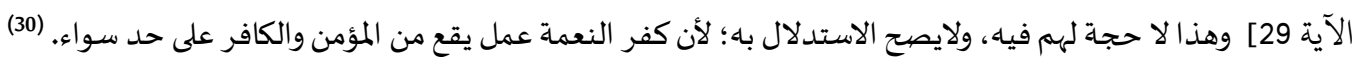

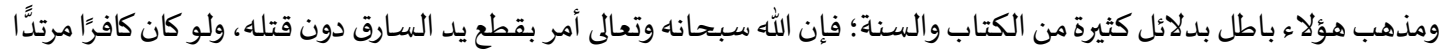

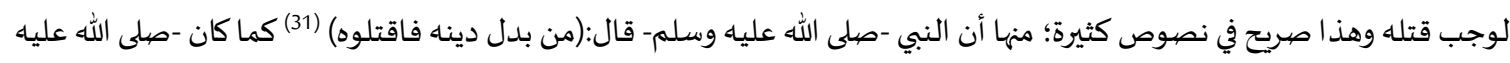

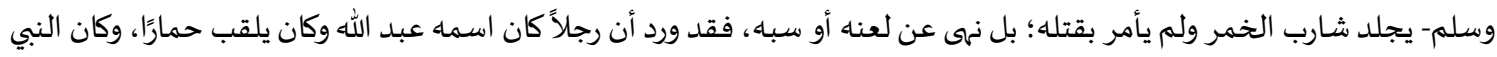

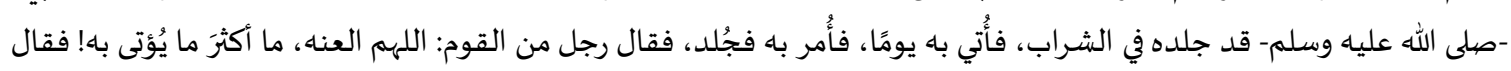

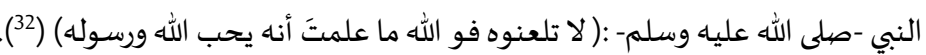

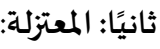

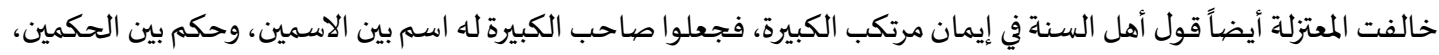

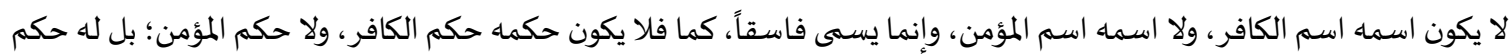

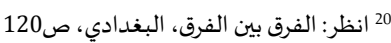

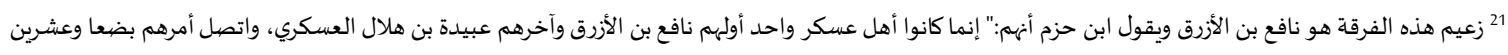

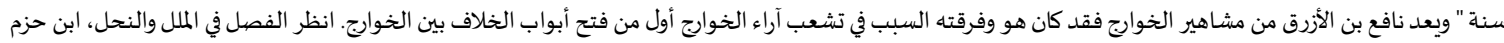

198/4،

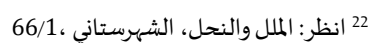

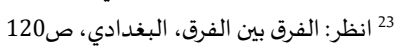

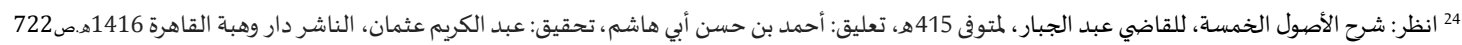

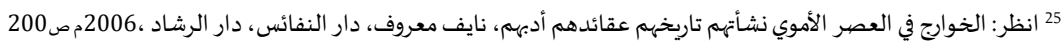

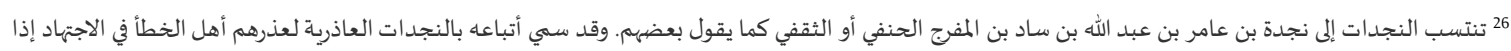

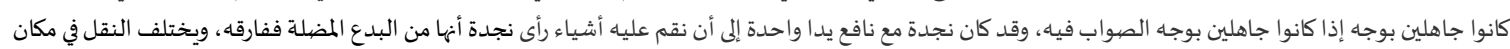

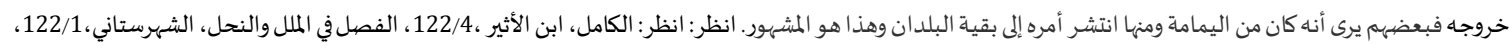

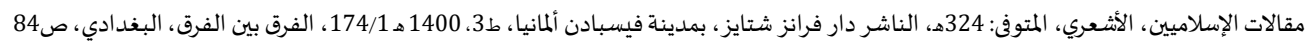

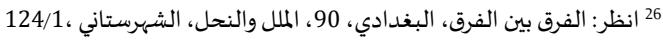

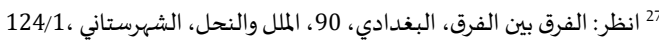

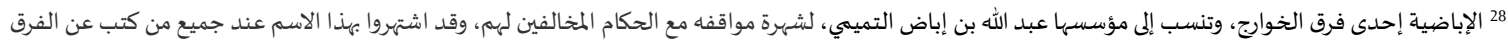

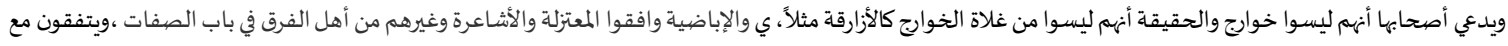

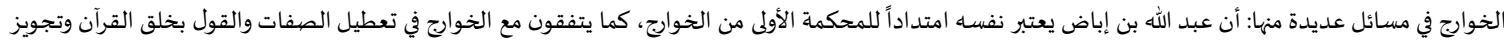

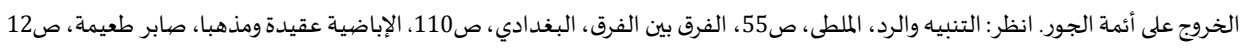

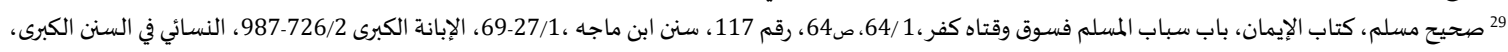




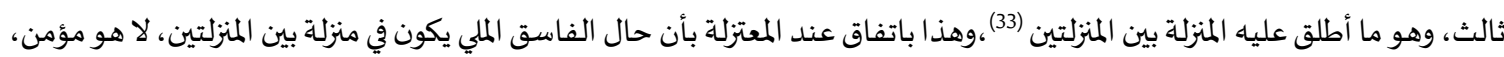

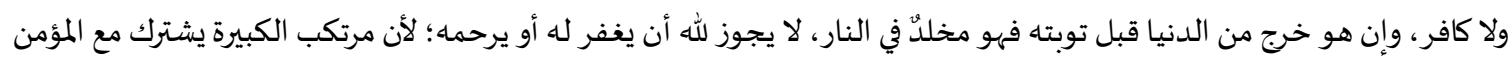

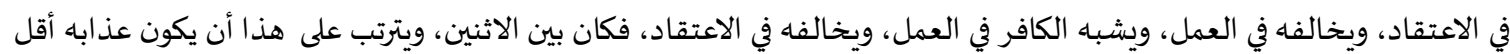
من عذاب الكافر، كما لا يستحق نعيم المؤمن (34).

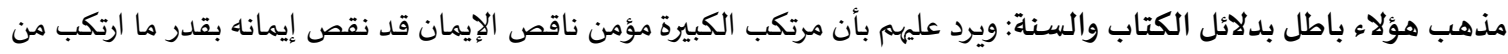

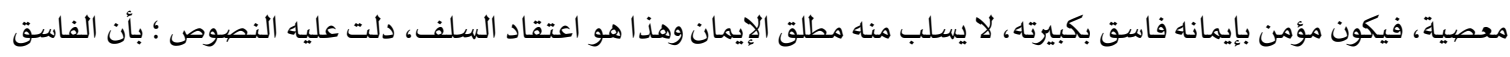

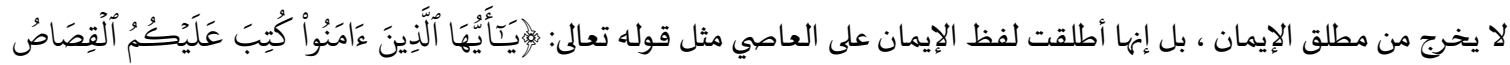

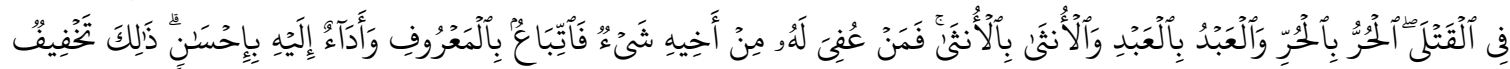

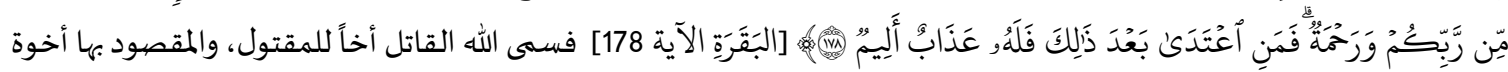

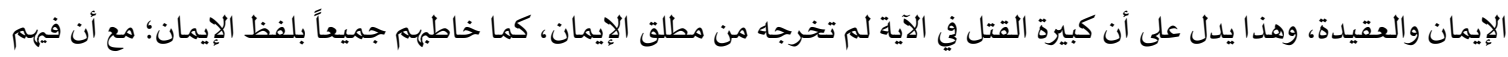

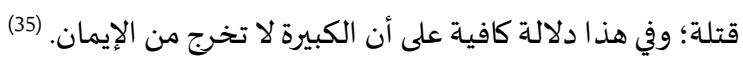

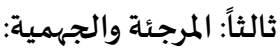

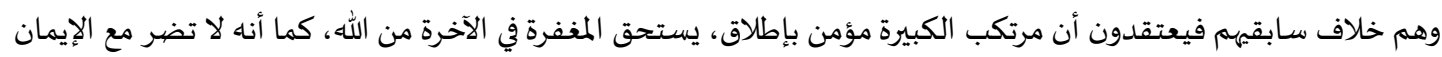

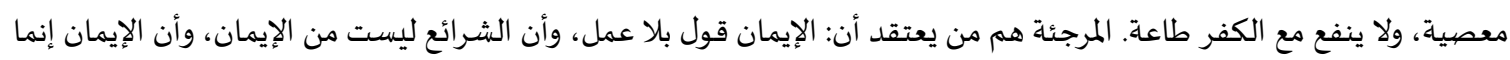

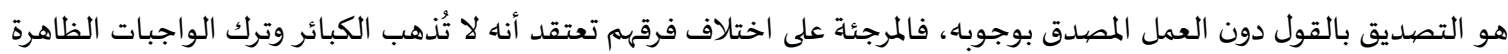

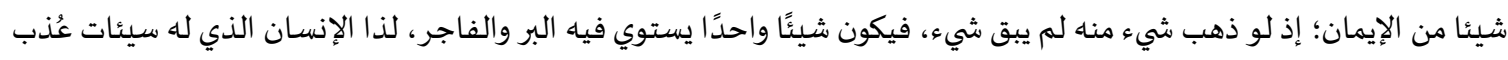

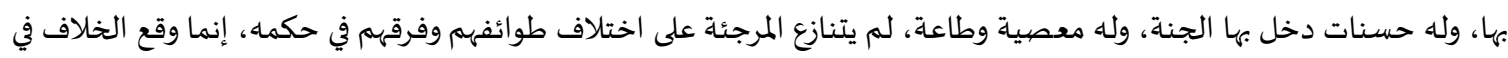

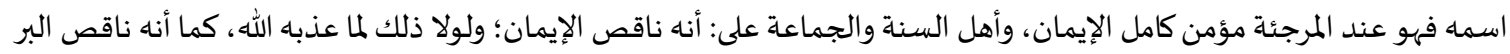

والتقوى باتفاق السلف. (36)

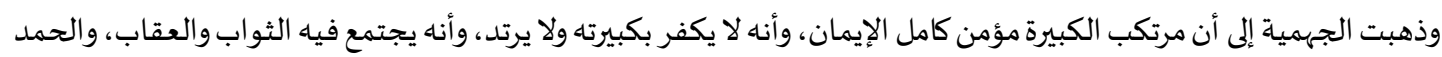

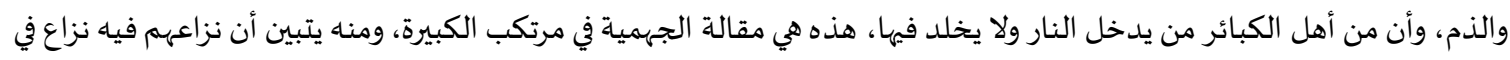

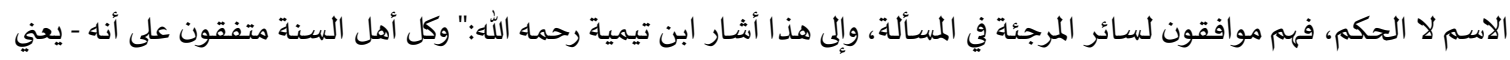

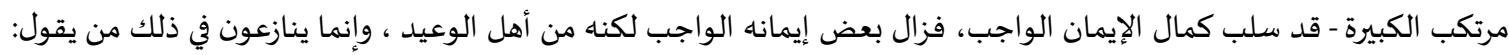

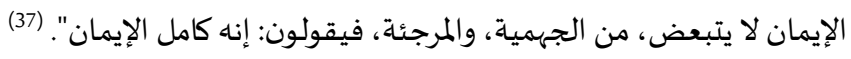

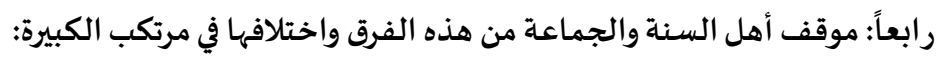

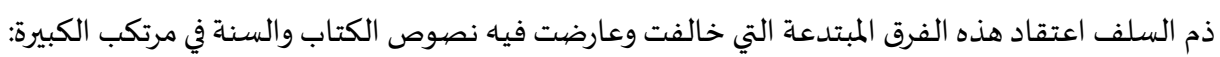

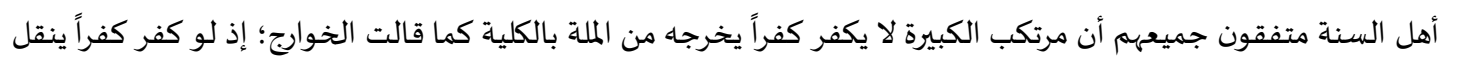

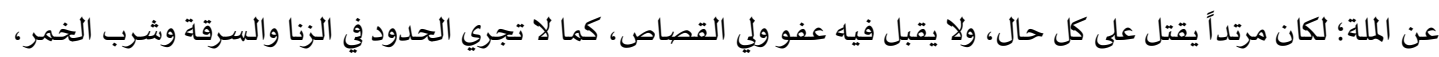
وزالت الحكمة من مشروعيتها في الإسلام.

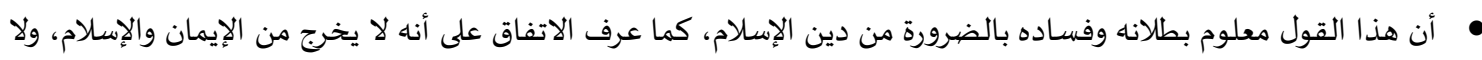

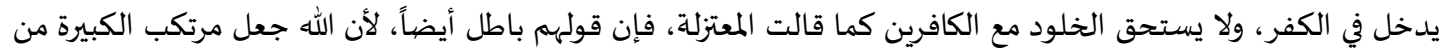

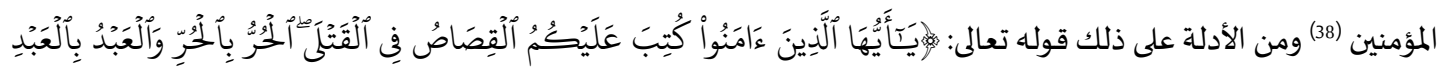

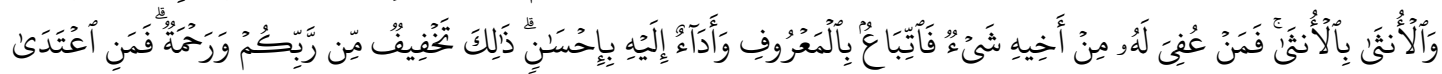

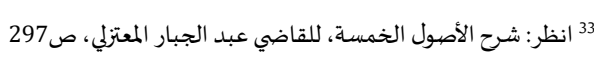

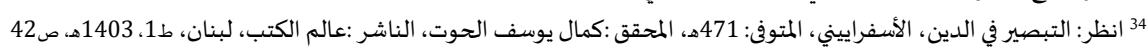

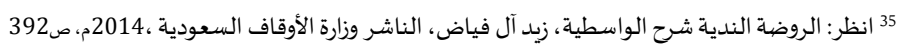

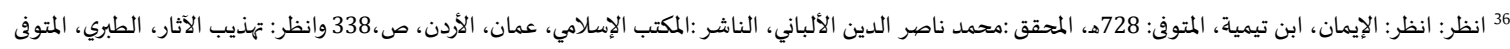

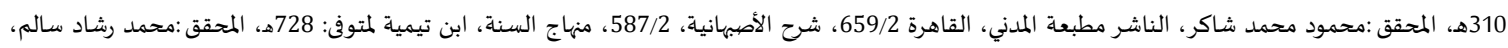

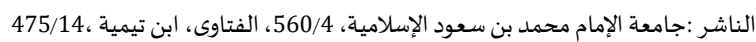

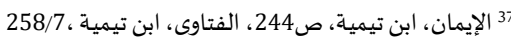

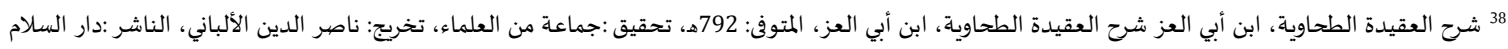

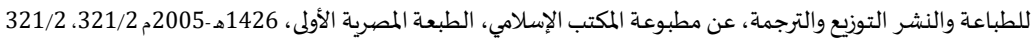




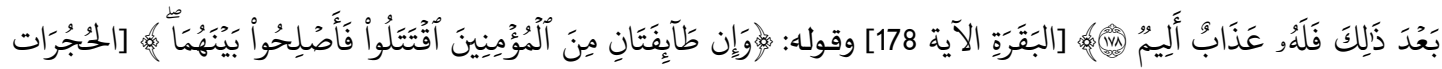

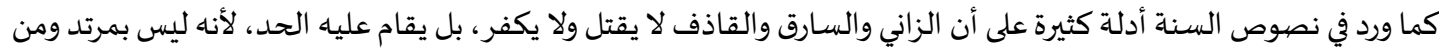

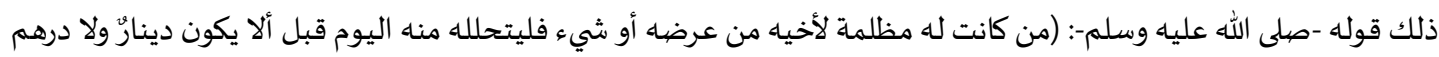

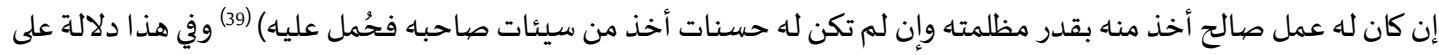

أن الظالم له حسنات يستوفي المظلوم منها حقه. (40)

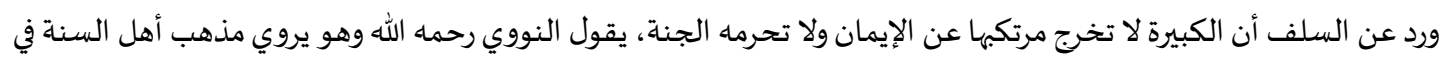

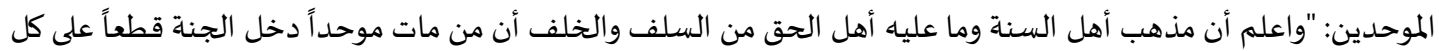
حال". (411) ويجاب عن أن ما ورد عن النبي -صلى الله عليه وسلم- في وصف معاصي المؤمنين بالكفر، يُحمل على الكفر الأصغر الذي لا يخرج

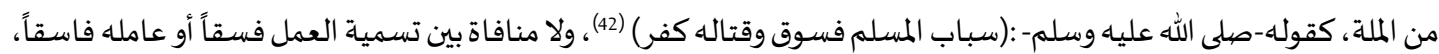

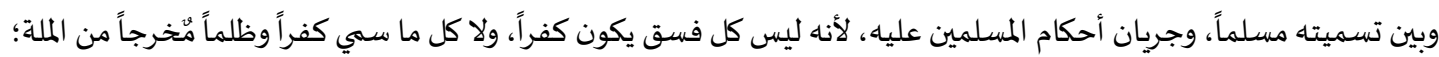

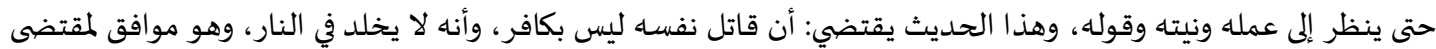

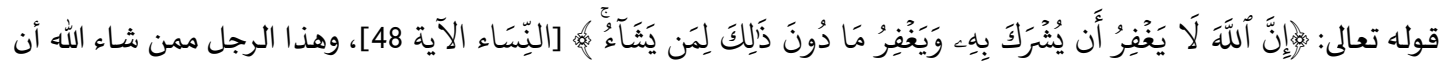

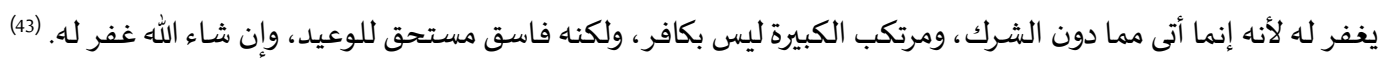

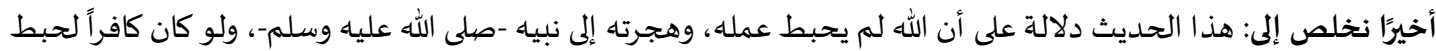

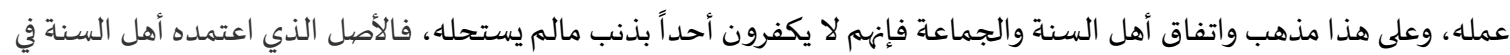

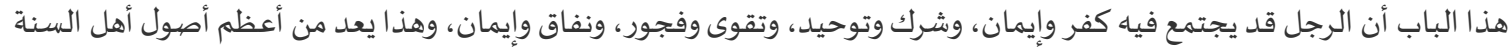

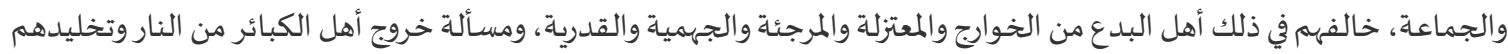

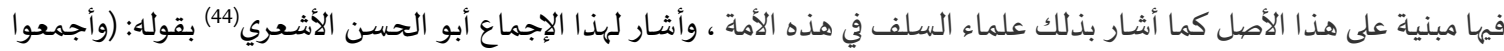

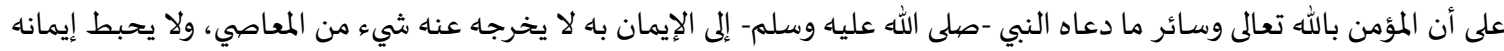

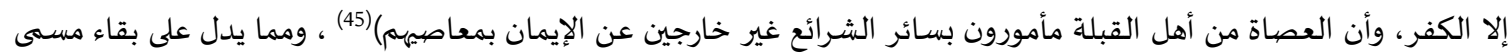
الإيمان له في هذا الخبر أن النبي -صلى الله عليه وسلم- قد استغفر لهانه.

المطلب الثاني: أن صاحب الكبيرة لا يخلّد في الناريوم القيامة:

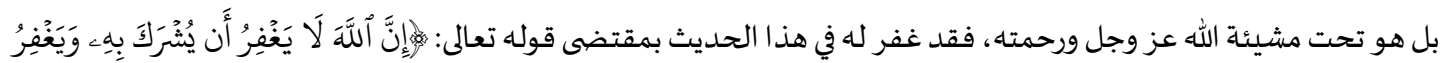

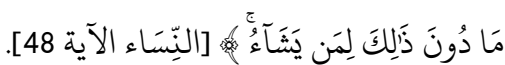

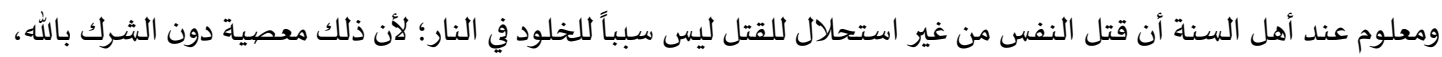

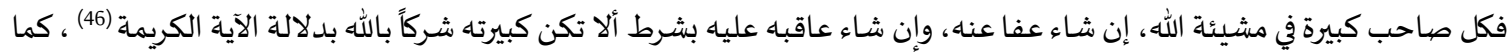

39 صحيح البخاري، كتاب المظالم، باب من كانت له مظلمة عند رجل، رقم 2317، وأخرج مسلم في صحيحة، معنى هذا الحديث "أتدرون من المفلس" كتاب البر والصلة، باب تحريم الظلم، رقم 4687 360 30 شرح العقيدة الطحاوية، ابن أبي العزب 217/1 صحيح مسلم بشرح النووي، أنظ : 42 سبق تخريجها

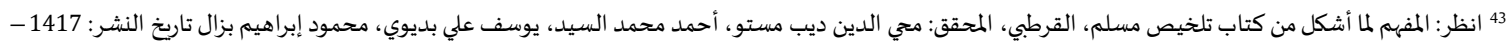

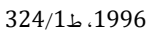
44 من نسل الصحابي أبي موسى الأشعري، وهو المنظر الأول لمواقف أهل السنة وإليه تنسب الأشعرية، كان من كبار الأئمة المجتهدين والمجدددين الذين حافظوا على عقيدة

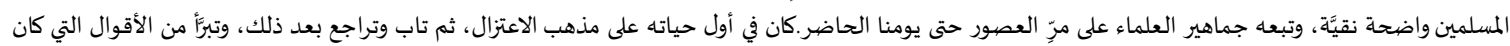

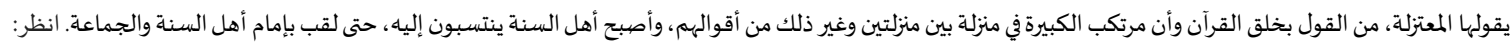

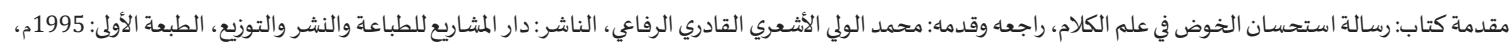
55 رسالة إلى أهل الثغر بباب الأبواب ، الأشعري ، المتوفى: 324ه، المحقق :عبد الله شاكر محمد الجنيدي، الناشر :عمادة البحث العلمي بالجامعة الإسلامية، المدينة المنورة، المملكة

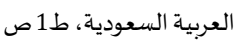
46 انظر: جامع البيان، الطبري، المتوفى 310ه، تحقيق :الدكتور عبد الله بن عبد المحسن التركي، بالتعاون مع مركز البحوث والدراسات الإسلامية بدار هجر الدكتور عبد السند

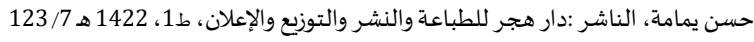


أن دعاء النبي -صلى الله عليه وسلم- له بالمففرة، دلالة أخرى على عدم خلوده في النار، أشار لذلك الطيبي رحمه الله عند شرحه للحديث:

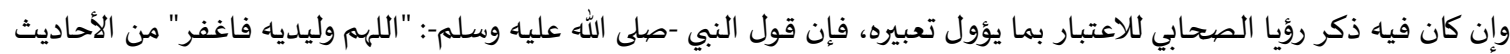

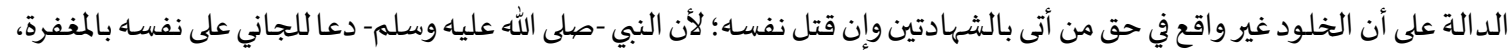

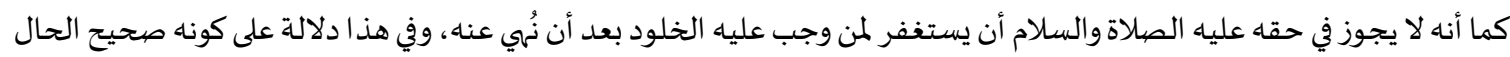

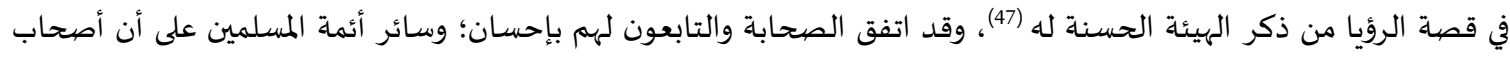

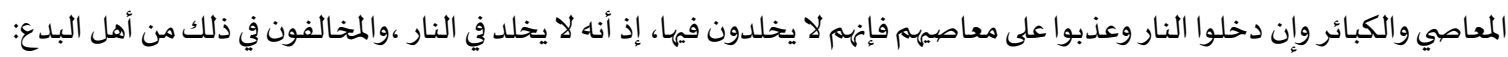

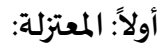

كان من رأي واصل بن عطاء في مرتكب الكبيرة أنه إذا خرج من الدنيا على كبيرة من غير توبة؛ يخالدا في النار؛ إذ ليس في الآخرة إلا

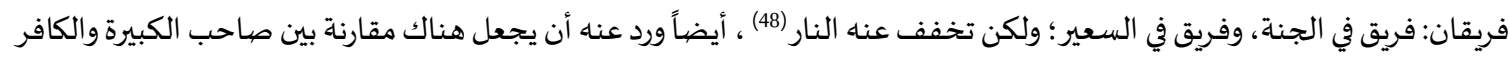

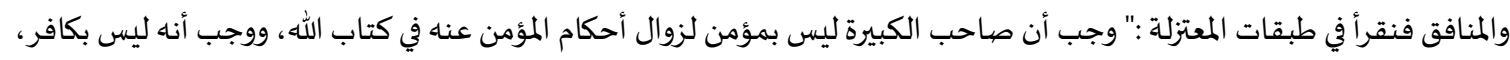

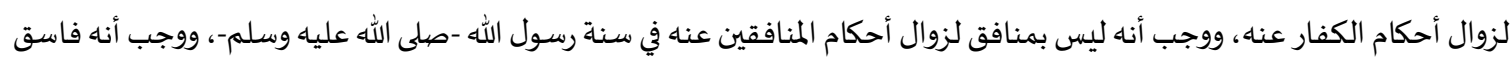

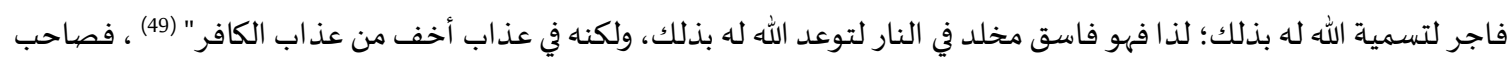

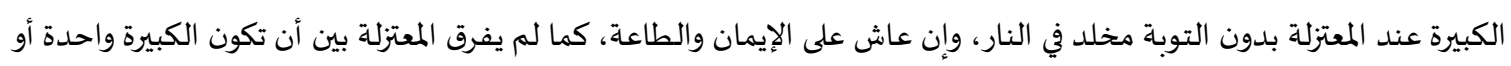

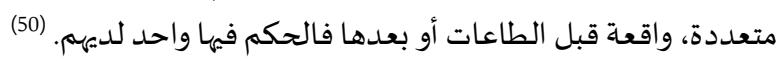

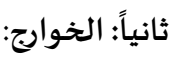

ذهب الخوارج إلى كفر مرتكب الكبيرة وخلوده في النار وأنه يعذب فهيها عذاب الكفار، وأجمعوا على ألى أن كل كبيرة كفر ، وأجمعوا

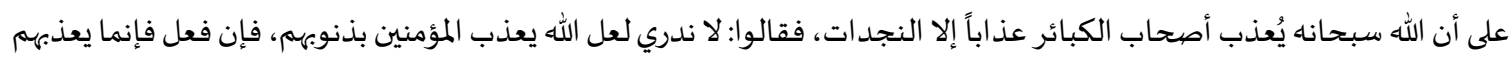

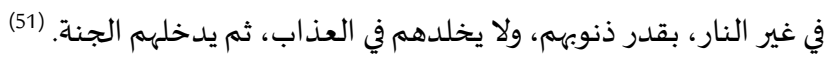

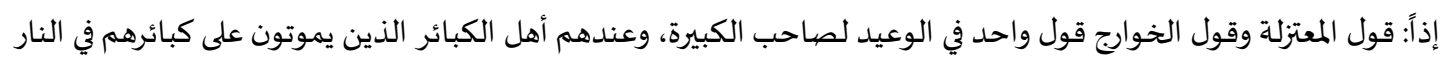

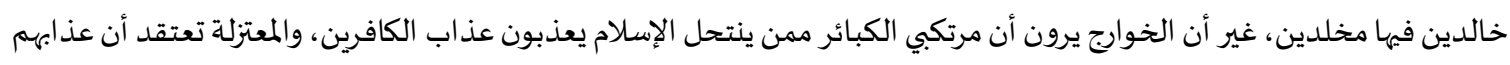
ليس كعذاب الكافرين. موقف أهل السنة والجماعة من ذلك:

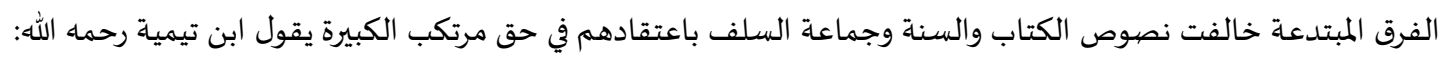

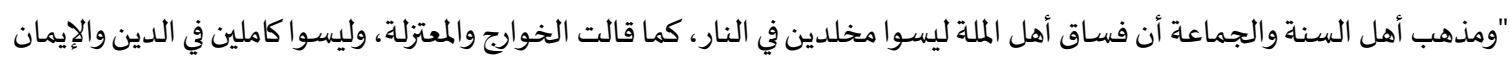

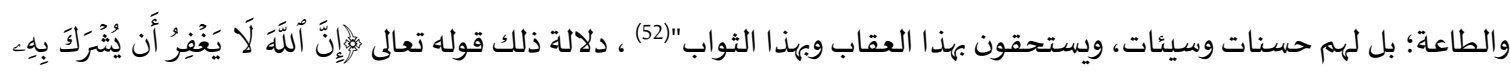

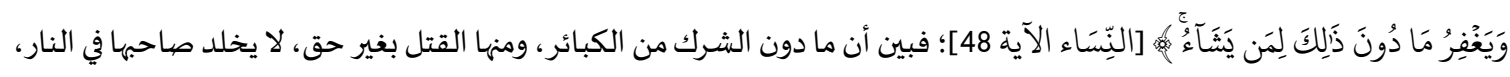

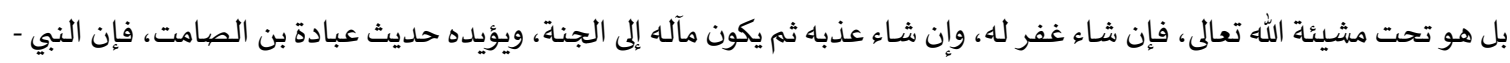

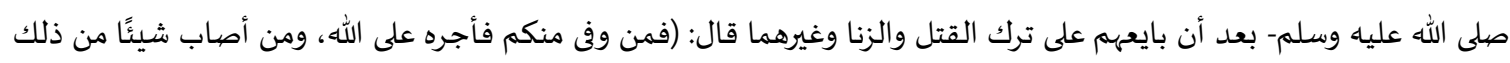

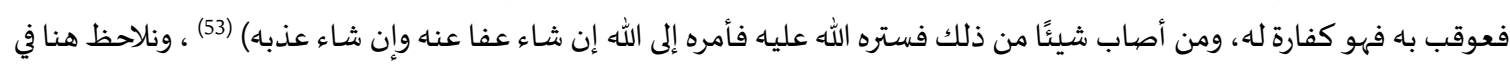

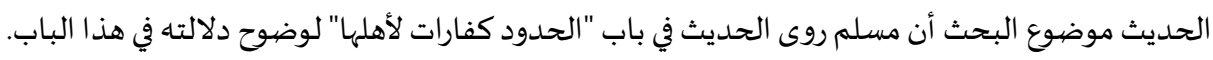

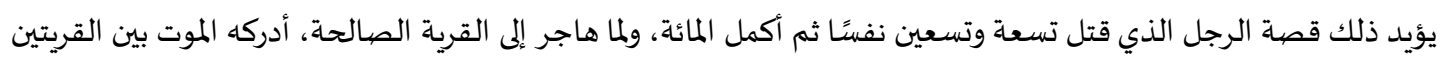

فقبضته ملائكة الرحمة والقصابة معلومة مشهورة. (54) فئل كذلك حديث أبي سعيد الخدري رضي الله عنه عن النبي -صلى الله عليه وسلم- قال: (يدخل أهل الجنة الجنة، وأهل النار النار

47 انظر: شرح المشكاة، للطيبي المتوفى 743هـ، المحقق :عبد الحميد هنداوي، الناشر :مكتبة نزار مصطفى الباز، مكة المكرمة، ط1، 1417هـ، 48

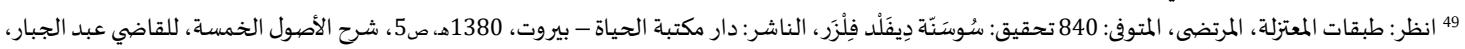


ثم يقول الله تعالى: أخرجوا من كان في قلبه مثقال ذرة من إيمان فيخرجوا منها قد اسودوا فيلقون في نهر الحيا أو الحياة فينبتون كما

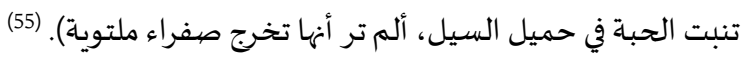

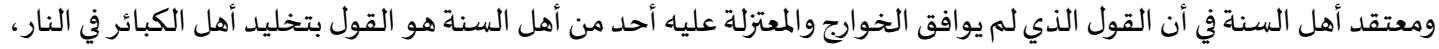

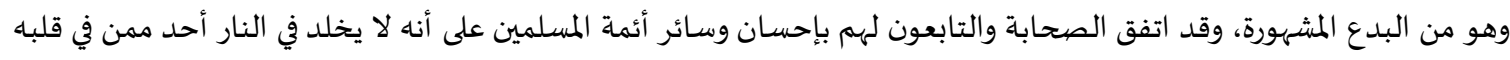

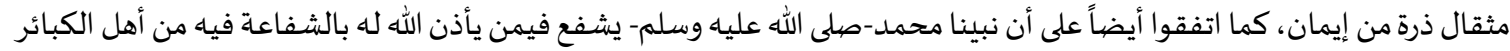

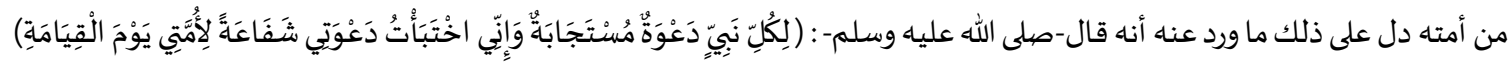

وهذا ما رجحها ابن تيمية(57) وتلميذه ابن القيم رحمهما الله، فقد أورد ابن القيم أقوال العلماء في المسألة ثم قال :" وقالت فرقة

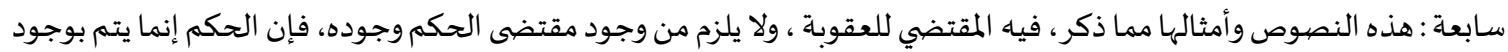

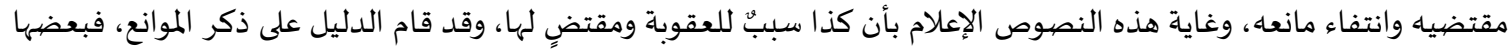

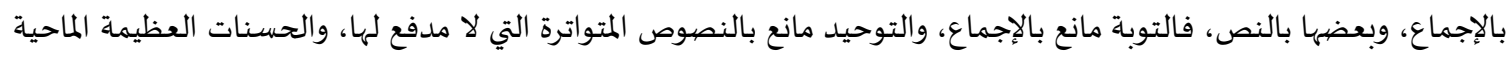

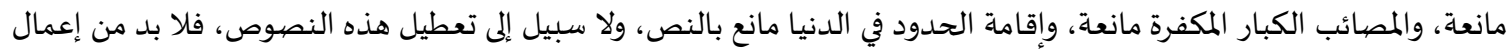
النصوص من الجانبين. (58)

المطلب الثالث: الاعتقاد بأن قتل النفس كبيرة من كبائر الذنوب:

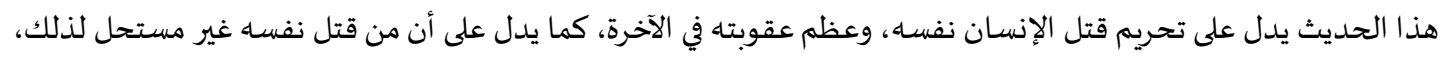

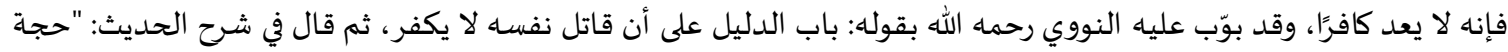

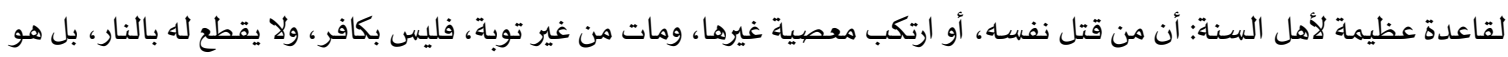

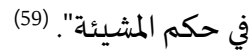

لهذا لا يجوز للإنسان أن يقتل نفسه، ولا أن يغرر بها في غير مصلحة شرعية ألمانة ، ولان أن أن يتصرف بشيء من أجزائها إلا بما يعود علهيها

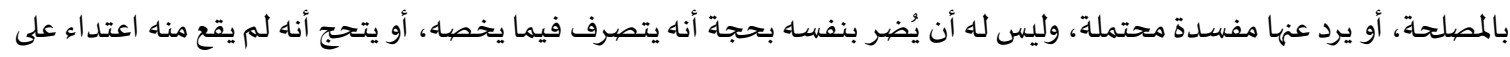

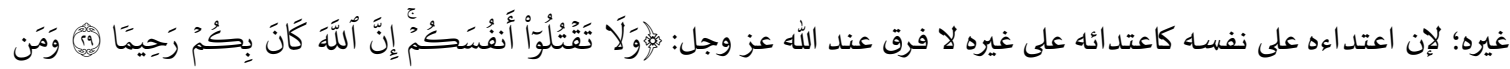

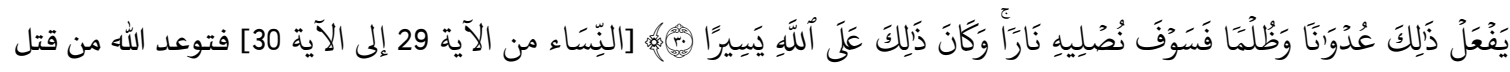

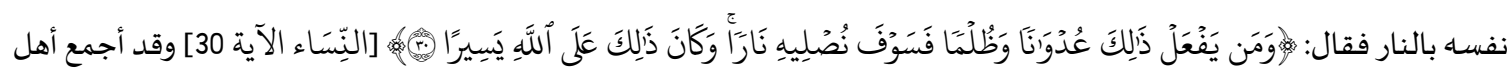

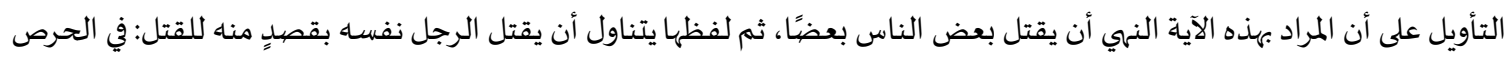

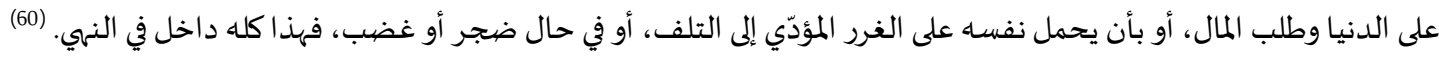

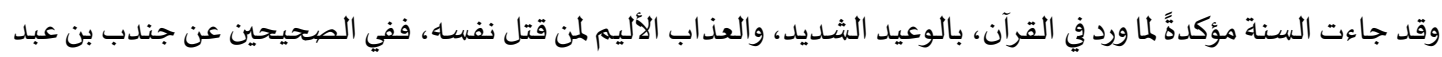

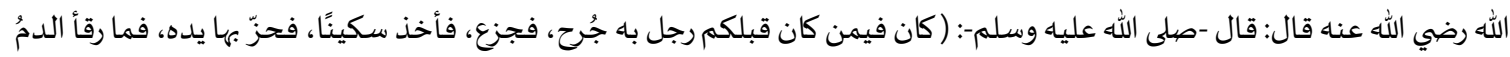

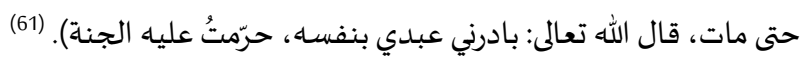

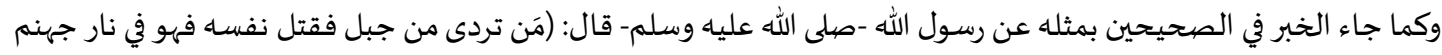

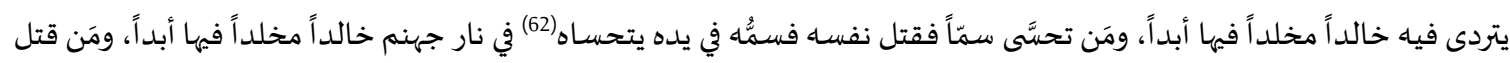

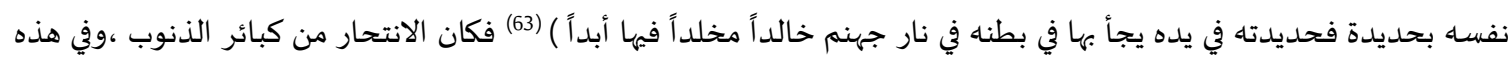

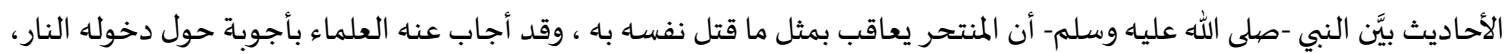
وهل يتنافى مع ما ذكرنا من جزاء المؤمنين ممن ارتكب كبائر وعدم القطع بكفرهم بأقوال المنها لمنها:

22 م5 55

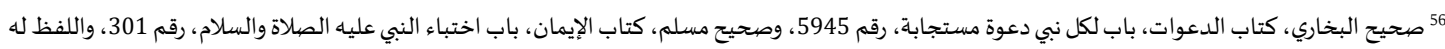

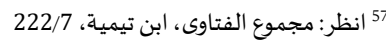

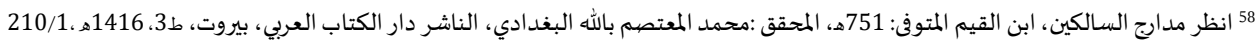

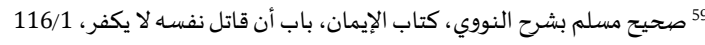

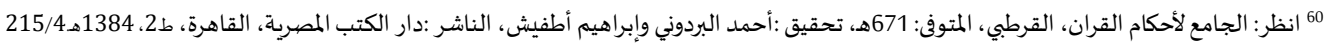

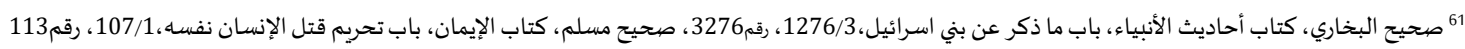

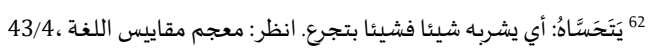

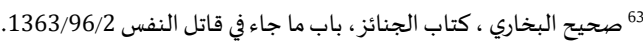


المقصود بذلك المستحل المعتقد جواز قتل النفس، والمستحل كافر كما بيَّنًا سابقاً. وقيل: هذا جزاؤه لو لم يتجاوز الله عنه.

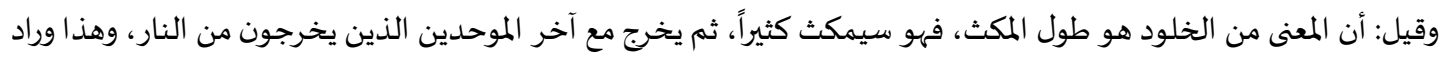

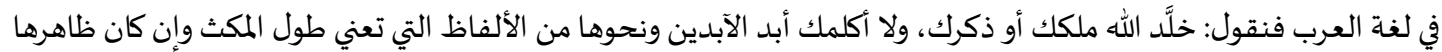

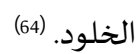

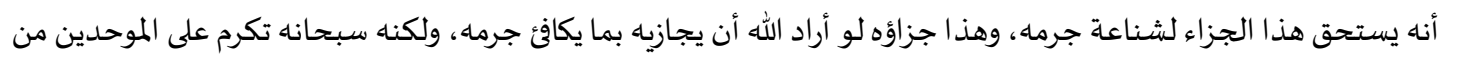

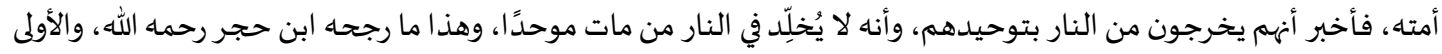

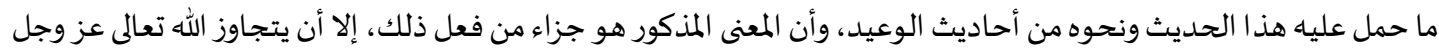
عنه. (65)

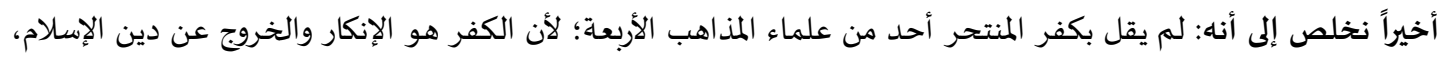

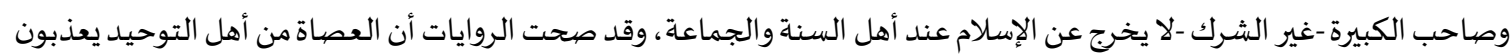

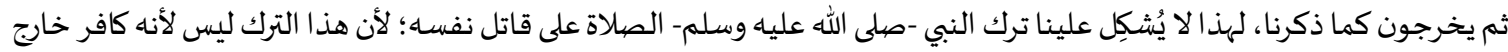

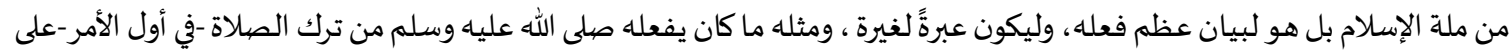

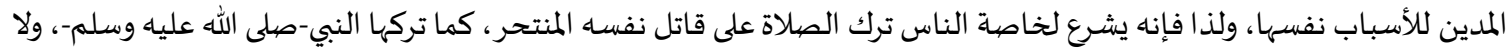

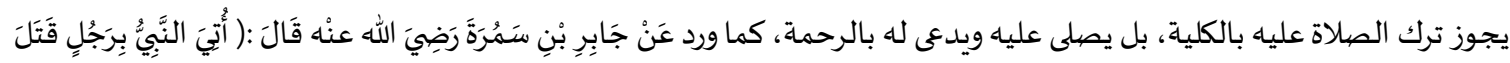

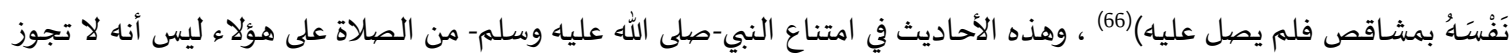

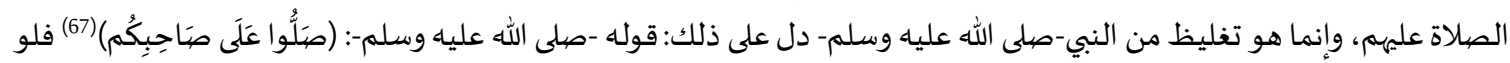

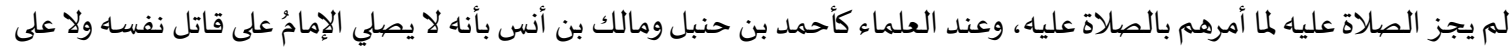

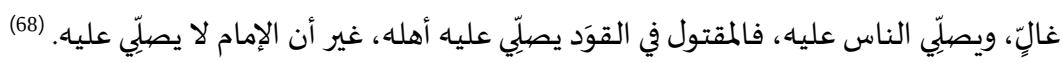

المطلب الر ابع: إثبات عقوبة بعض أصحاب المعاصي:

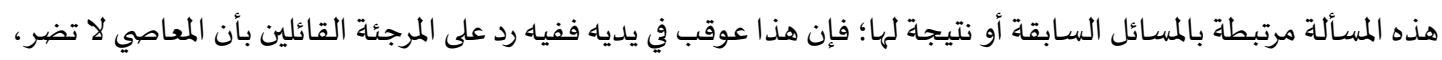

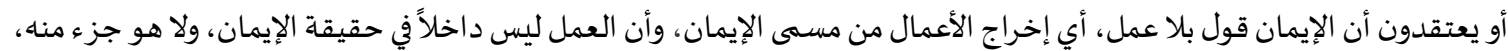

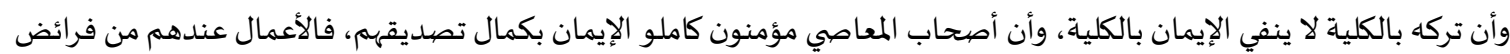

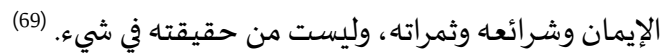

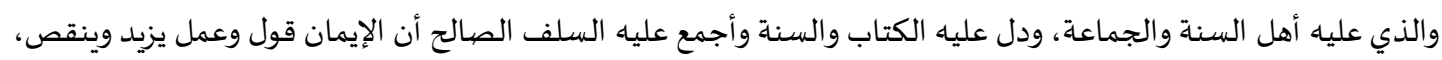

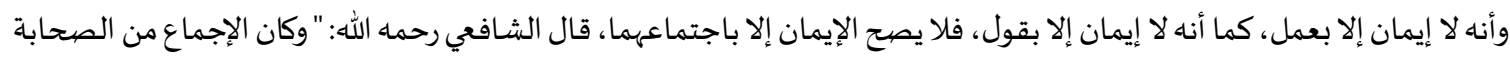

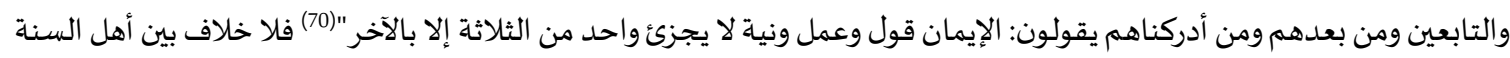

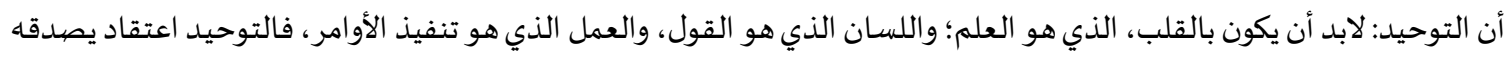

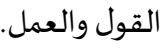

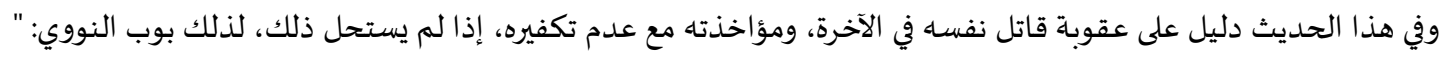

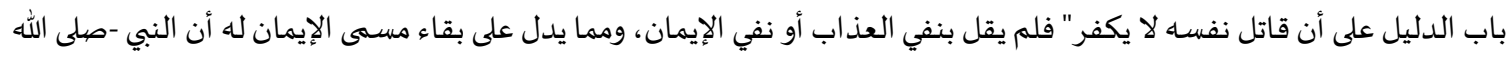

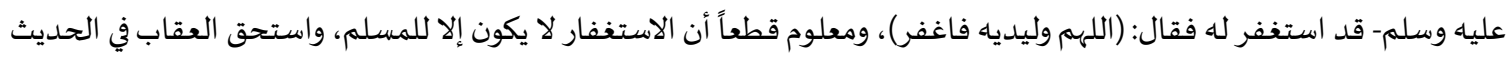
لمعصيته بقطع يديه.

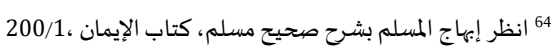

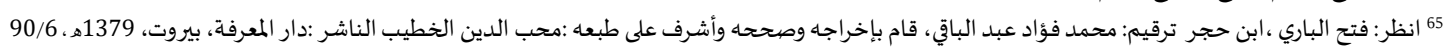

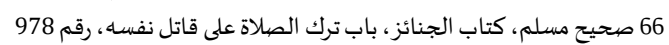

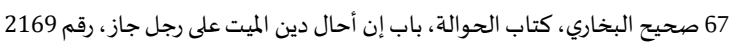

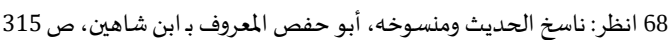

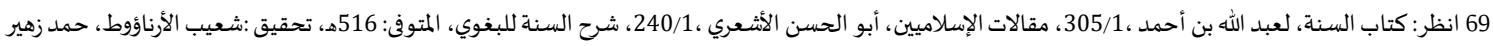

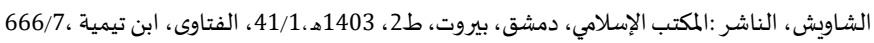

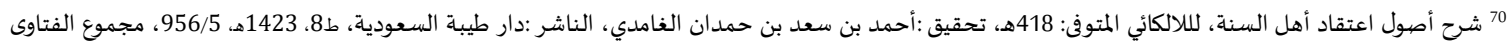

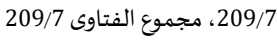


المطلب الخامس: الاعتقاد بشفاعة النبي -صلى الله عليه وسلم- في أهل الكبائر:

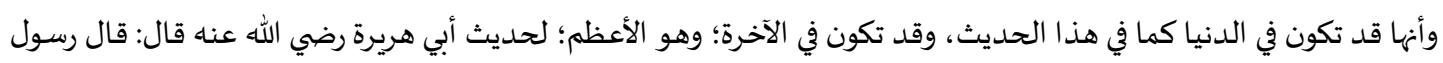

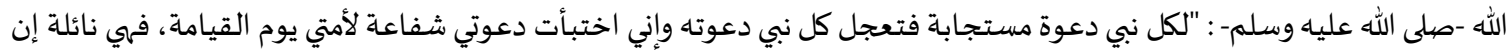

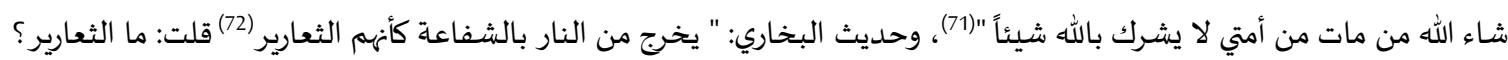

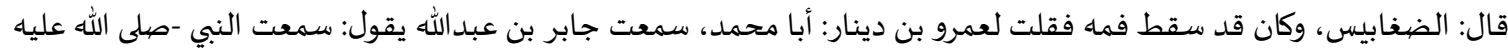

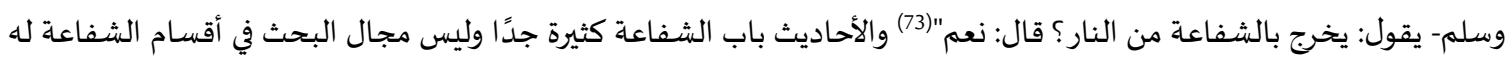

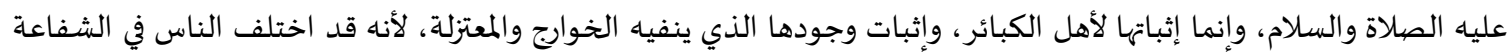

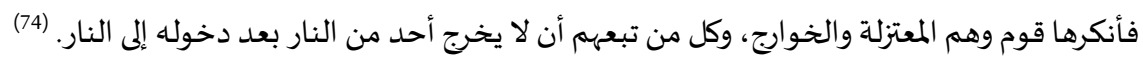

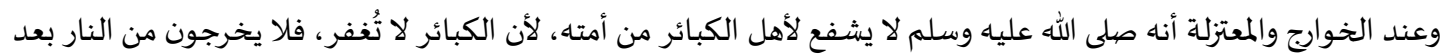

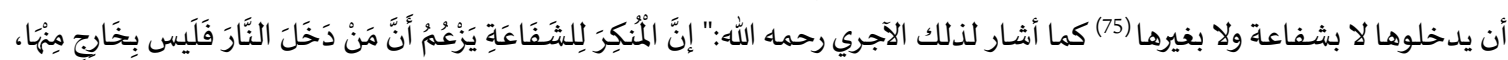

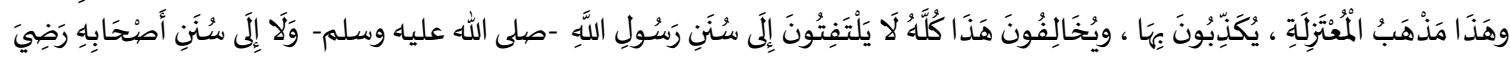

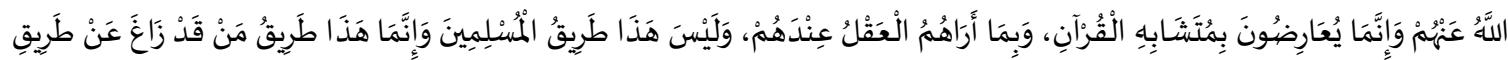

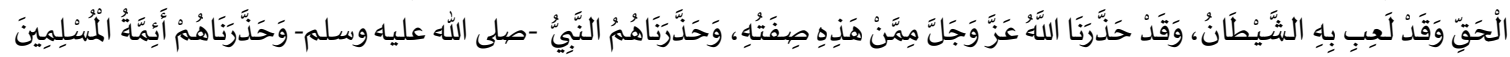

قَدِيمًا وَحَدِيثًا". (76)

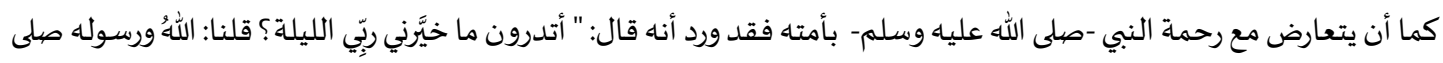

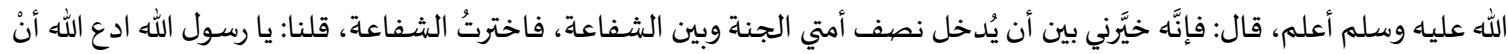

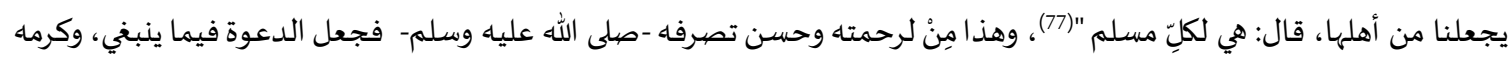

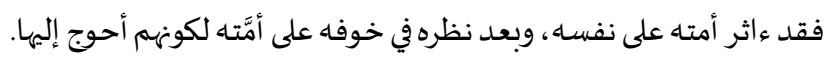

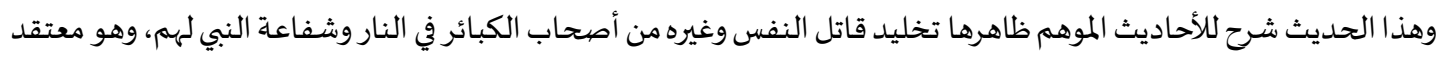

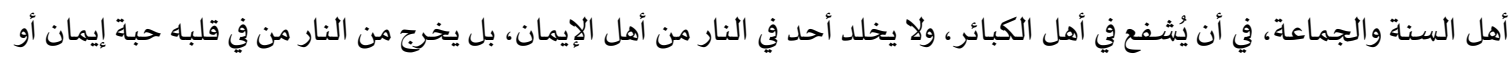
مثقال ذرة. (78)

المطلب السادس: أهمية الرؤى في الإسلام وأنها قد تكون سبباً لثبوت بعض الأحكام الشرعية:

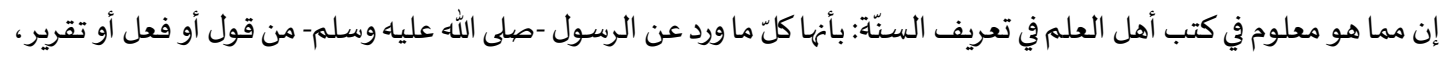

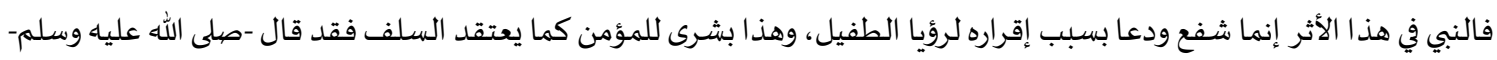

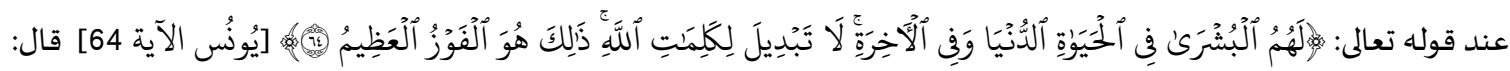

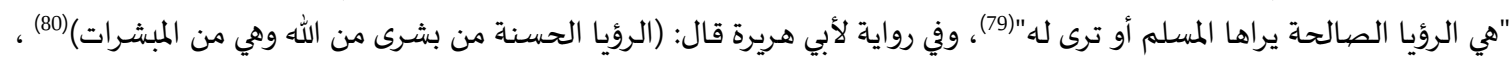
والرؤيا تعد صالحة وبشارة إذا صدرت من أهل الصددق والصلاح قال -صلى الله عليه وسلم-: " إذا اقترب الزمان لمان لم تكن رؤيا المسلم

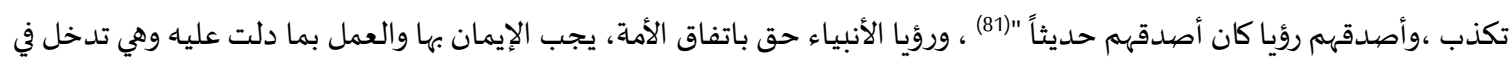

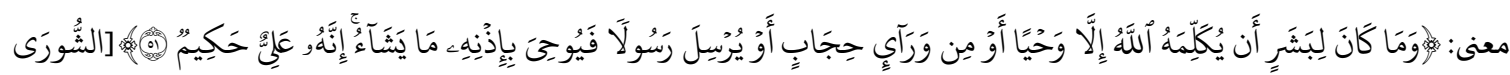

71 سبق تخريجها 72 الثعارير: بمثلثة مفتوحة ثم مهملة أي كعصفور، انظر: فتح الباري، ابن حجر كتاب الرقاق، باب صفية الجنة والنار،123/8

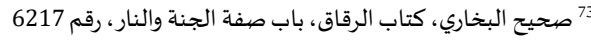

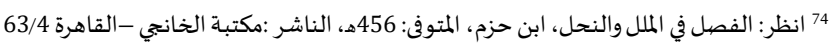

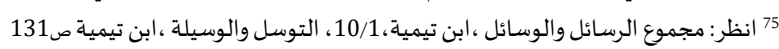

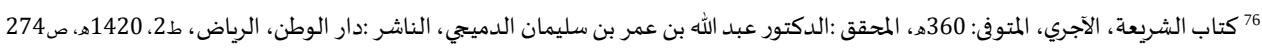

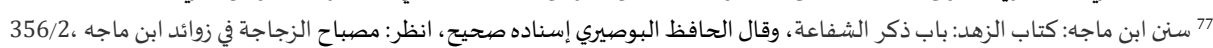

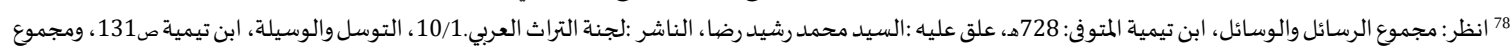

116/1، الفتاوى، لابن تيمية

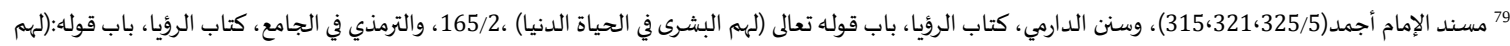

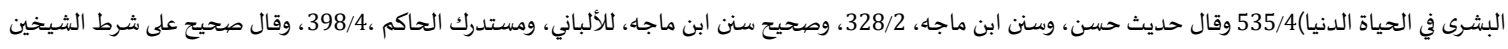

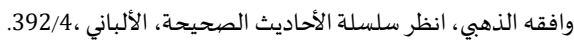
80

81 مسند الإمام أحمد ، 269،507/2، وصحيح مسلم بشح النووي، 20/15 وسنن الدارمي ،168/2، كتاب الرؤيا، باب أصدق الناس رؤيا أصدقهم حديثا. 
الآية 51] كذلك يقال في الرؤى التي رآها النبي -صلى الله عليه وسلم- يجب الإيمان بما دلت عليه والعمل بها أمراً ونهيا. (82) وكذلك رؤيا الصحابة التي أقرها النبي -صلى الله عليه وسلم- وقد ورد في ذلك أمثلة كثيرة منها إقراره للأذان (83)، وقولنه-صلى الله

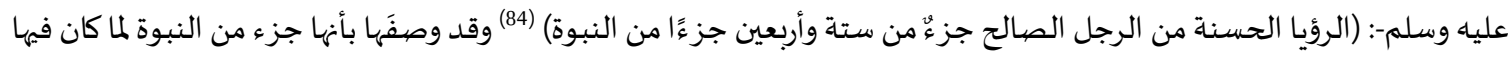

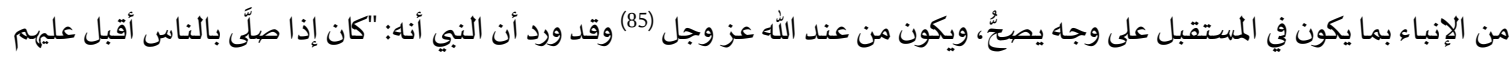

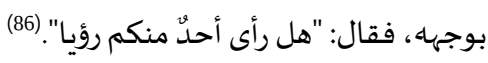
فكان شأن الرؤيا عنده عليه الصلاة والسلام عظيم، لذا كان يسأل عنها كلَّ يوم؛ لأنها من أخبار الغيب، ولههم في ذلك نفع في أمر

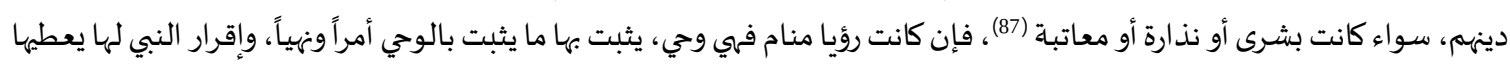

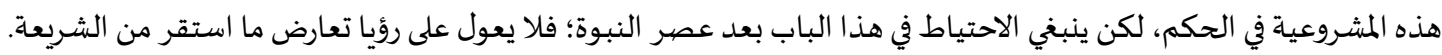

المطلب السـابع: الاعتقاد بفضل الهجرة والصحبة:

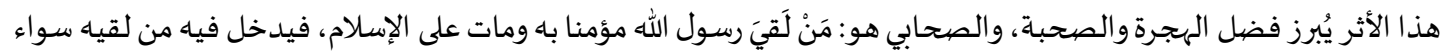

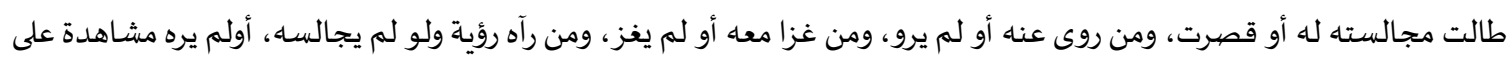

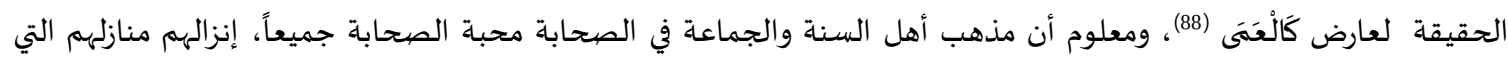
يستحقونها بالعدل، فلا يرفعونهم إلى ما لا يستحقون، ولا يقصُرون بهم عما يليق بهم؛ ألسنتهم رطبة بذكرهم الحسن اللائق بهم،

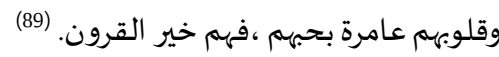

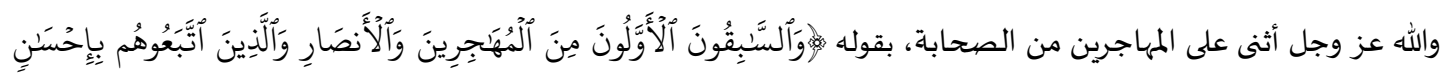

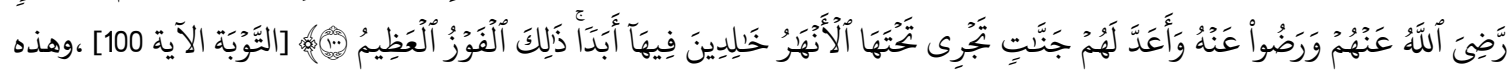

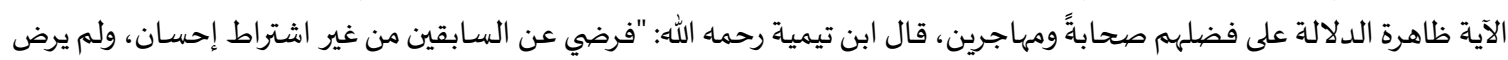

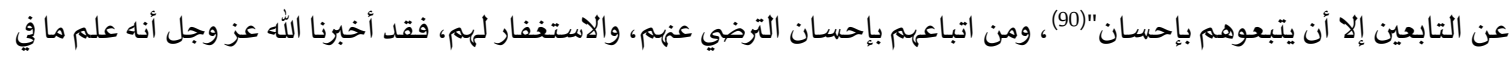

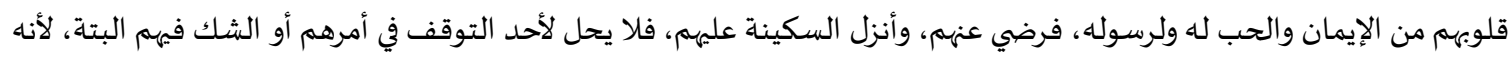

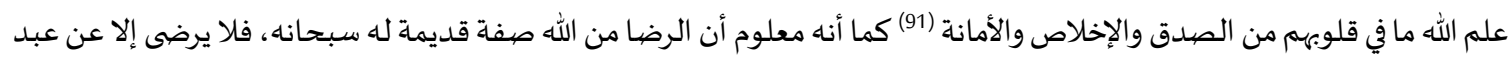

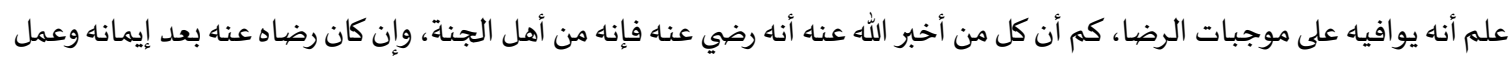

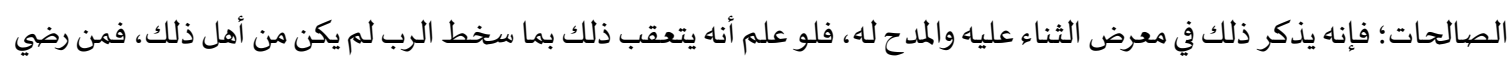

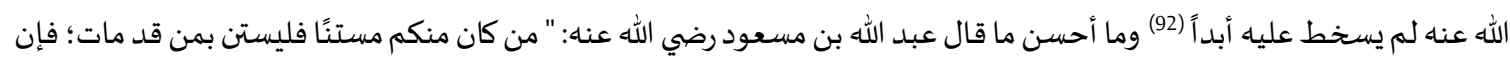
الحي لا تؤمن عليه الفتنة؛ أولئك أصحاب محمد -صلى الله عليه وسلم- كانوا أفضل هذه الأمة؛؛ أبرها قلوباً وأعمقها علماً وأقلها تكلفاً، قوم اختارهم الله لصحبة نبيه وإقامة دينه، فاعرفوا لهم فضلهم واتبعوهم في آثارهم، وتمسكوا بما استطعتم من أخلاقهم ودينهم،

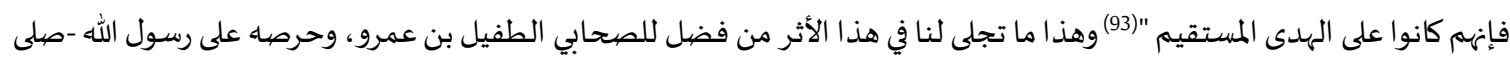

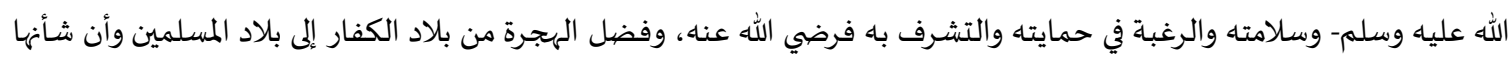

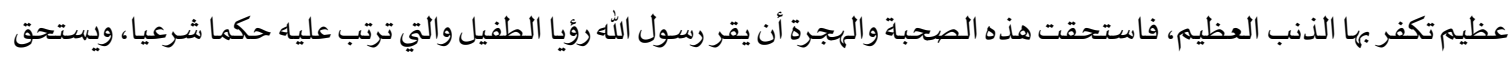

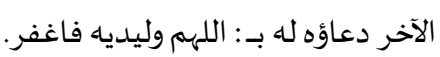

82 انظر: مدارج السالكين، ابن القيم،62/1، وانظر: فتح المجيد شرح كتاب التوحيد، للشيخ عبد الرحمن حسن آل الشيخ، ص 613

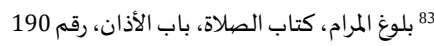

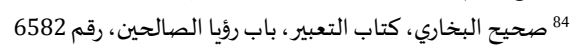

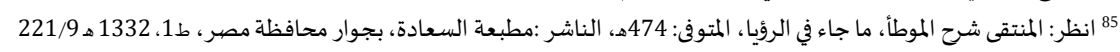

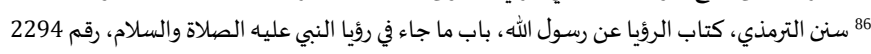

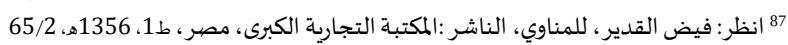

88

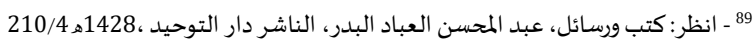

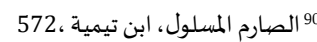

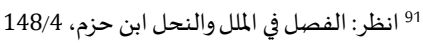

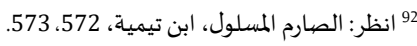
93 


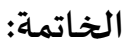

أحمد الله عز وجل أن من عليَّ بدراسة هذا الأثر عن رسول الله عليه الصلاة والسلام، ومن خلال دراسة هذه المطالب المختلفة

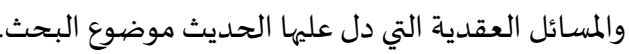

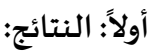

يمكن أن نلخص أهم النتائج التي تناولها الدراسة:

خالفت الفرق المبتدعة نصوص الكتاب والسنة وجماعة السلف باعتقادهم في حق مرتكب الكبيرة، وهذا الحديث يرد علها بإبراز

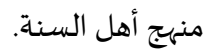

ه أن الإيمان قول وعمل يزيد وينقص، وأنه لا إيمان إلا بعمل، كما أنه لا إيمان إلا بقول، فلا يصح الإيمان إلا باجتماعهما وهذا ما

$$
\text { دل عليه الكتاب والسنة. }
$$

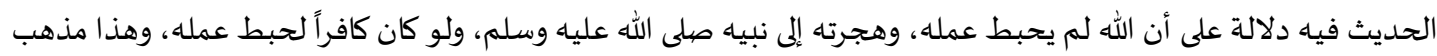

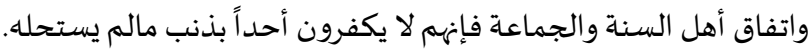

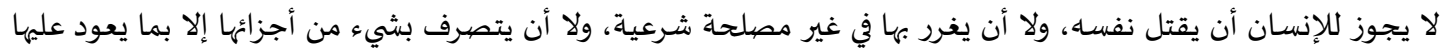

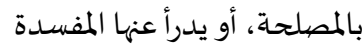

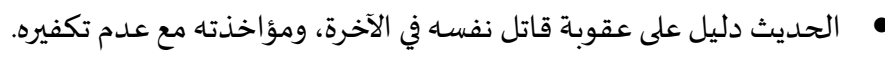
• الاعتقاد بأن قتل النفس كبيرة من كبائر الذنوب.

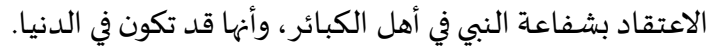
وإقرار النبي لرؤيا الطفيل يعطهيا المشروعية في الحكم. فضل الصحابي الطفيل بن عمرو، وإسلامه وأسبقيتها في ذلك، يبرز أهمية الصحبة في الإسلام. ثانياً: التوصيات: • العناية بالرد على المخالفات العقدية وأهل البدع، من خلال دراسة الحديث النبوي، واعتماد منهج السلف في الرد.

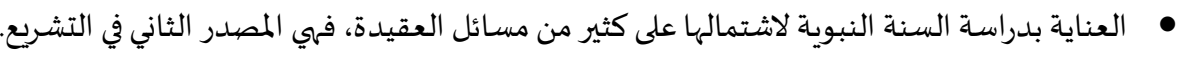

• طرح واعتماد المشاريع العلمية المتعلقة بدراسة السنة النبوية، وتأكيدها على مسائل الإيمان الكبرى. • التعاون مع مراكز البحث العلمي وكراسي البحث في الجامعات، ومراكز الدعوة، بتقديم دروس العلمية والأبحاث المتعلقة بالسنة النبوية ودلالتها على قضايا الإيمان.

1. ابن أبي العز، علي (2005). شحح العقيدة الطحاوية. (ط1). (تحقيق :جماعة من العلماء).(تخريج: ناصر الدين الألباني). دار

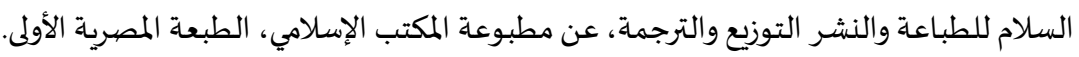

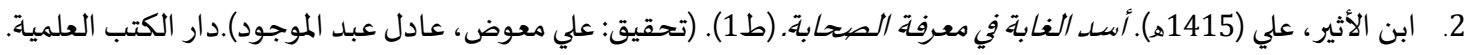

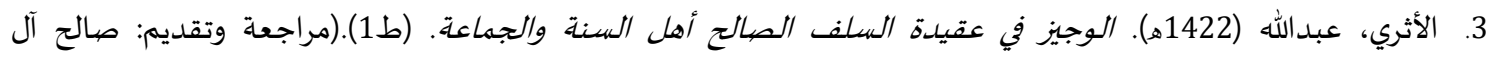

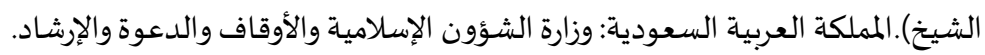

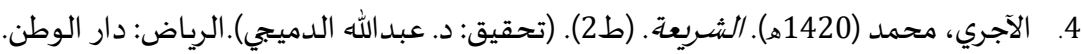
5. الأسفراييني، طاهر (1403ه). التبصير في الدين وتمييز الفرقة الناجية عن الفرق الهالكين. (ط1).(تحقيق: كمال الحوت).لبنان: عالم الكتب. 6. الأسفراييني، عبدالقاهر (د.ت). الفرق بين الفرق وبيان الفرقة الناجية. (د.ط).بيروت: دار الآفاق الجديدة.

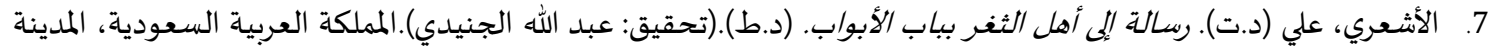
المنورة: عمادة البحث العلمي بالجامعة الإسلامية. 8. الشعري، علي (د.ت). مقالات الإسلاميين واختاف المصيلين. (ط3). فيسبادن، ألمانيا: دار فرانز شتايز.

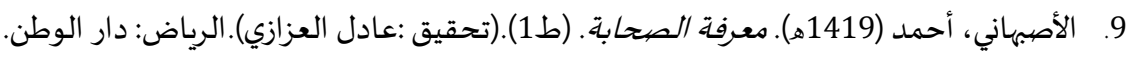

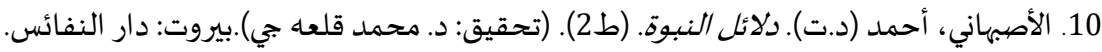


11. الأندلسي، سليمان (1332ه). المنتقى شرح الموطأ. (ط1). بجوار محافظة مصر: مطبعة السعادة.

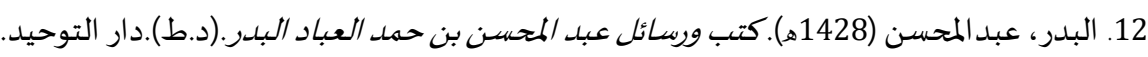

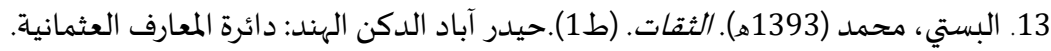

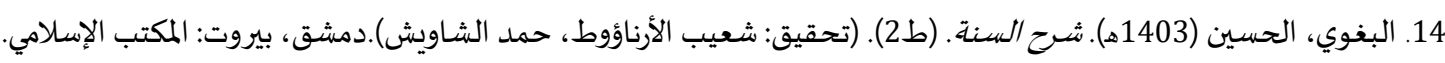

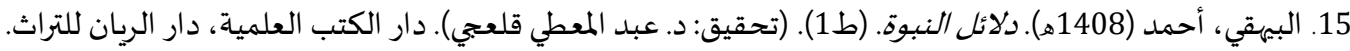

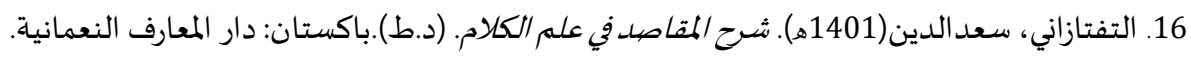

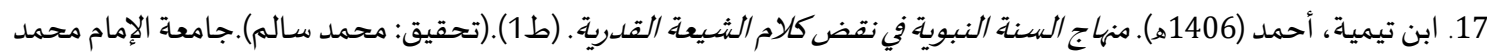

بن سعود الإسلامية.

18. ابن تيمية، أحمد (1416ه). الإيمان. (ط5).(تحقيق: محمد الألباني).عمان، الأردن: :المكتب الإسلامي.

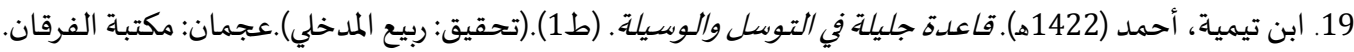

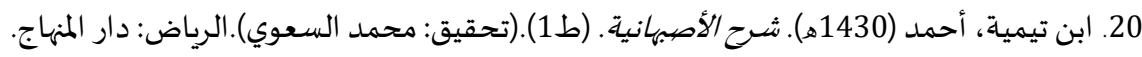

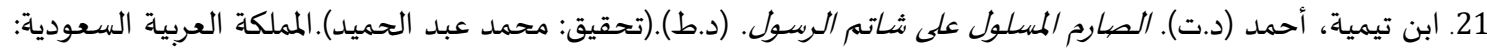

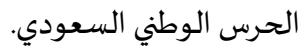

22. ابن تيمية، أحمد (د.ت). مجموع الفتاوى. (د.ط).(تحقيق: عبد الرحمن بن قاسم).المدينة المنورة، المملكة العربية السعودية: مجمع الملك فهد لطباعة المصحف الشريف. 23. ابن تيمية، أحمد (د.ت). مجموعة الرسائل والمسائل. (د.ط).(تعليق: السيد محمد رضا). لجنة التراثة المعاث العربي.

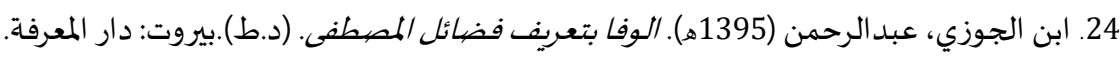

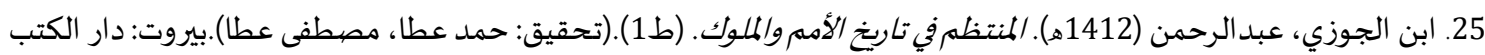
العليمة.

26. ابن حجر، أحمد (1415ه). الإصابة في تمييز الصحابة. (ط1).(تحقيق :عادل عبد الموجود، وعلى معوض). بيروت: دار الكتب العلمية. 27. ابن حجر، أحمد (د.ت). فتح الباري شَح صحيح البخاري. (د.ط).(ترقيم: محمد عبد الباقي).( قام بإخراجه وصححاه وأشرف على الميل طبعه: محب الدين الخطيب).بيروت: دار المعرفة.

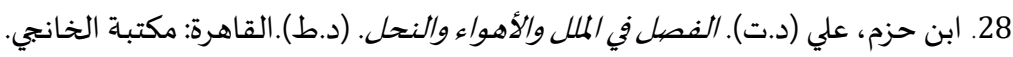

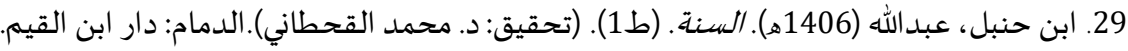

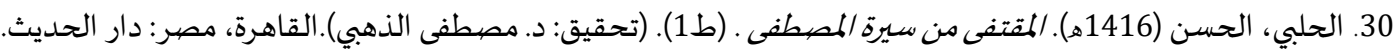
31. الذهبي، شمس الدين (1405ه). سير أعلام النباء. (ط3).(تحقيق: مجموعة من المحققين بإشراف الشيخ شعيب الأرناؤوط). مؤسسة الرسالة.

32. الزهري، محمد (د.ت). الطبقات الكابرى. (د.ط).(تحقيق: علي عمر).مكتبة الخانجي.

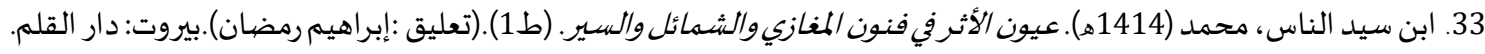

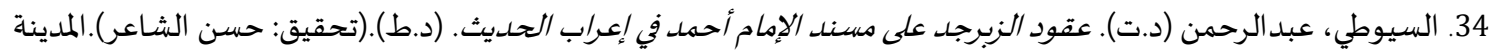
المنورة: مجلة الجامعة الإسلامية.

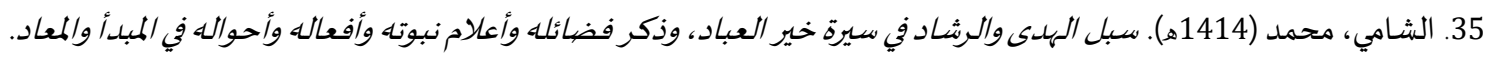

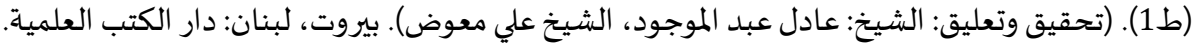

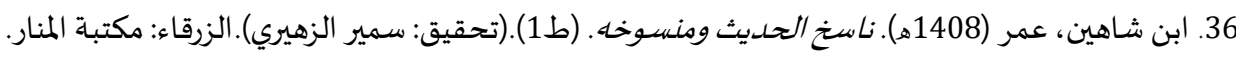

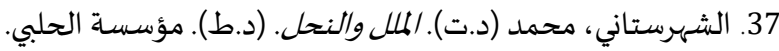

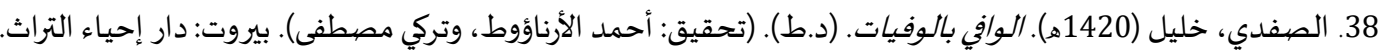

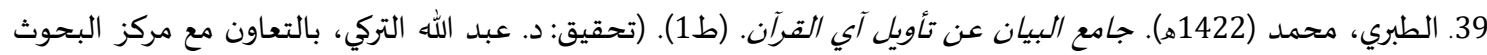

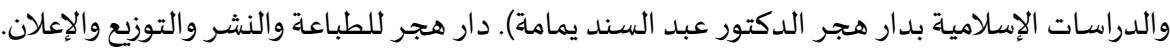

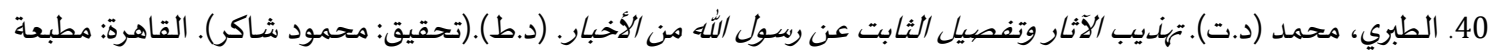


42. الطيبي، الحسين (1417ه). شح الطيبي على مشكاة المصابيح المسهى بـا(الكاشف عن حقائق السنن). (ط1).(تحقيق: عبد الحميد هنداوي). مكة المكرمة: مكتبة نزار مصطفى الباز.

43. ابن عبد البر، يوسف (1412ه). الاستيعاب في معرفة الأصحاب. (ط 1).(تحقيق: علي البجاوي).بيروت: دار الجيل.

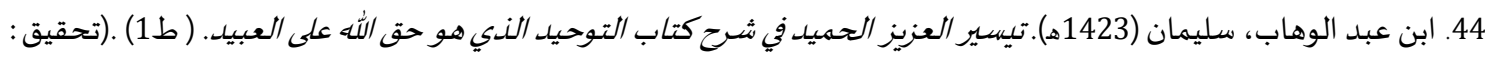

$$
\text { زهير الشاويش). دمشق، بيروت: المكتب الاسلامي. }
$$

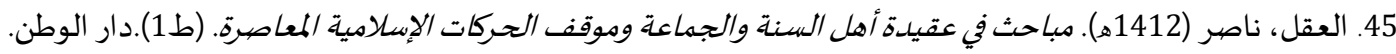

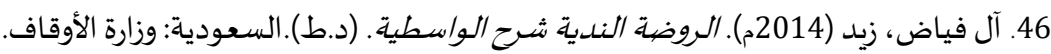

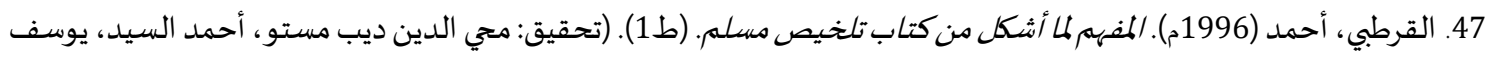
بديوي، محمود بزال). (د.ن). 48. القرطبي، محمد (1384ه). الجامع لأحكام القرآن. (ط2).(تحقيق :أحمد البردوني وإبراهيم أطفيش). القاهرة: دار الكتب المصرية.

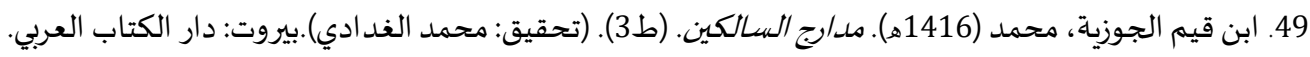

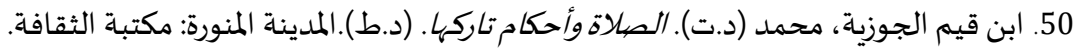

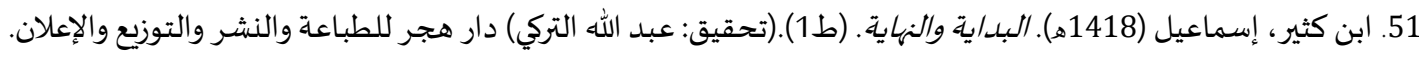

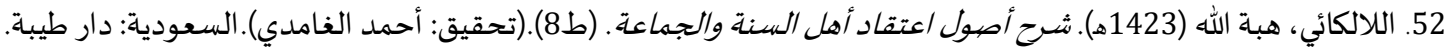

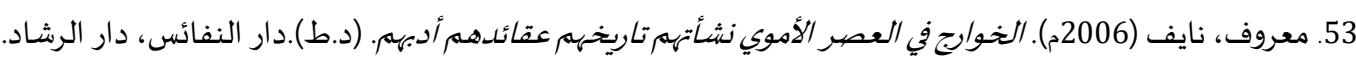

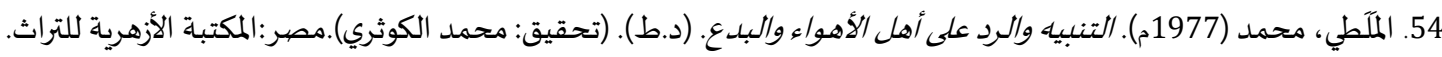

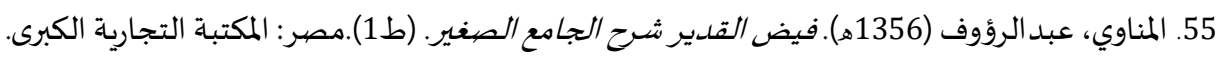

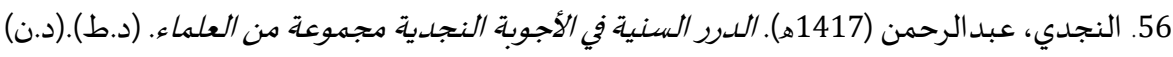

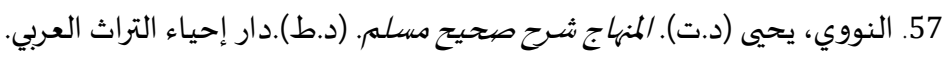

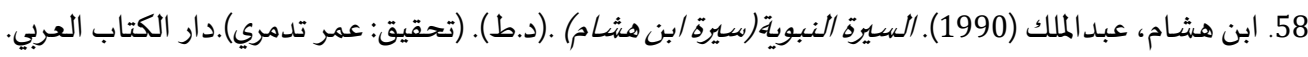

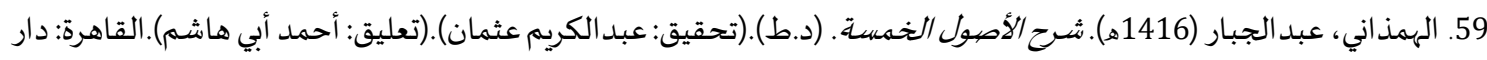
وهبة.

60. وزارة الأوقاف والشئون الإسلامية(1427هـ).الموسوعة الفقهية الكويتية.(ط2).الكويت: دار السلاسل. 
المجلة الدولية للدراسات الإسلامية المتخصصية

International Journal of Specialized Islamic Studies (SIS)

www.refaad.com Journal Homepage: https://www.refaad.com/views/SIS/Home.aspx

ISSN: 2617-6246(Online) 2617-6238(Print)

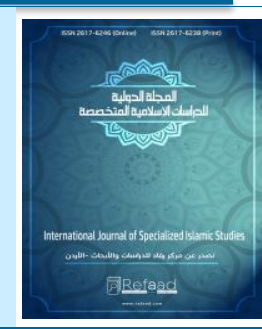

\section{O Allah, grant pardon even to his sons "Is a creed study" Research summary}

\section{Badria bint Mohammad Al-Fawzan}

Professor of Creed, College of Education, Islamic Studies, King Saud University, Saudi Arabia balfawzan@ksu.edu.sa

Received: 3/10/2021 Revised: 26/10/2021 Accepted: 1/11/2021 DOI: https://doi.org/10.31559/SIS2021.6.2.5

Abstract: This research is titled "Streptococcal Issues" in the talk of "God and his two sons, forgive" a decadelong study. The text of the Hadith in question contains a number of issues of faith and creed that are the subject of a response to those who deviated from the difference in the concept of faith and the perpetrator of the major sins, highlighting these issues and responding to them according to the belief of the Sunnis , the community highlights of the problem of this study, its importance and the consideration of the controls of faith, atonement, and the treatment of some deviations in the case of the perpetrator of the major sins. This is conducted through the belief of Ahl al-Sunnah and those who disagree with it from the sects through the text of the Prophet's Hadith according to an analytical and inferential approach represented in "analysis and eliciting" the issues of belief in the text of the Hadith. The research concluded that: contrary to the texts of the Quran and Sunnah and the group of Salaf in their belief in the right of the perpetrator of the major sins, and it is indicative that God did not frustrate the work of those who killed themselves while they are believers and emigrated to the religion of God and his prophet peace be upon him. If they are infidels to frustrate their work, and on this doctrine and agreement of the Sunnis and the Congregation, they do not disbelieve anyone with a sin that they do not solve, so it is necessary to take care of the study of the Prophet's Sunnah to include it in many of faith issues, they are the second source of legislation.

Keywords: Creed; The great culprit; Atonement; Faith.

\section{References:}

1. Abn Aby Al'z, 'ly (2005). Shrh Al'qydh Althawyh. (T1). (Thqyq: Jma't Mn Al'lma'. (Tkhryj: Nasr Aldyn Alalbany). Dar Alslam Lltba'h Walnshr Altwzy' Waltrjmh, 'n Mtbw't Almktb Aleslamy, Altb'h Almsryh Alawla.

2. Alajry, Mhmd (1420h). Alshry'eh. (T2). (Thqyq: D. 'Ebdallh Aldmyjy).Alryad: Dar Alwtn.

3. Alandlsy, Slyman (1332h). Almntqa Shrh Almwta. (T1). Bjwar Mhafzt Msr: Mtb't Als'adh.

4. Alasbhany, Ahmd (1419h). M'rft Alshabh. (T1). (Thqyq: 'adl Al'zazy). Alryad: Dar Alwtn.

5. Alasbhany, Ahmd (D.T). Dla'l Alnbwh. (T2). (Thqyq: D. Mhmd Ql'h Jy). Byrwt: Dar Alnfa's.

6. Alasfrayyny, Tahr (1403h). Altbsyr Fy Aldyn Wtmyyz Alfrqh Alnajyh 'n Alfrq Alhalkyn. (T1). (Thqyq: Kmal Alhwt).Lbnan: 'alm Alktb.

7. Alasfrayyny, 'bdalqahr (D.T). Alfrq Byn Alfrq Wbyan Alfrqh Alnajyh. (D.T).Byrwt: Dar Alafaq Aljdydh.

8. Alash'ry, 'ly (D.T). Rsalt Ela Ahl Althghr Bbab Alabwab. (D.T). (Thqyq: 'Ebd Allh Aljnydy). Almmlkh Al'rbyh Als'wdyh, Almdynh Almnwrh: 'madt Albhth Al'Imy Baljam'h Aleslamyh.

9. Alash'ry, 'ly (D.T). Mqalat Aleslamyyn Wakhtlaf Almslyn. (T3). Fysbadn, Almanya: Dar Franz Shtayz.

10. Abn Alathyr, 'ly (1415h). Asd Alghabh Fy M'rft Alshabh (T1). (Thqyq: 'ly M'wd, 'adl 'bd Almwjwd). Dar Alktb Al'lmyh.

11. Alathry, 'bdallh (1422h). Alwjyz Fy 'qydh Alslf Alsalh Ahl Alsnh Waljma'h. (T1). (Mraj'h Wtqdym: Salh Al Alshykh). Almmlkh Al'rbyh Als'wdyh: Wzart Alsh'wn Aleslamyh Walawqaf Wald'wh Walershad. 
12. Albdr, 'bdalmhsn (1428h). Ktb Wrsa'l 'bd Almhsn Bn Hmd Al'bad Albdr.(D.T).Dar Altwhyd.

13. Albghwy, Alhsyn (1403h). Shrh Alsnh. (T2). (Thqyq: Sh'yb Alarna'wt, Hmd Alshawysh).Dmshq, Byrwt: Almktb Aleslamy.

14. Albsty, Mhmd (1393h). Althqat. (T1).Hydr Abad Aldkn Alhnd: Da'rtAlm'arf Al'thmanyh.

15. Albyhqy, Ahmd (1408h). Dla'l Alnbwh. (T1). (Thqyq: D. 'bd Alm'ty Ql'jy). Dar Alktb Al'lmyh, Dar Alryan Lltrath.

16. Abn Hjr, Ahmd (1415h). Alesabh Fy Tmyyz Alshabh. (T1). (Thqyq: 'adl 'bd Almwjwd, W'la M'wd). Byrwt: Dar Alktb Al'lmyh.

17. Abn Hjr, Ahmd (D.T). Fth Albary Shrh Shyh Albkhary. (D.T). (Trqym: Mhmd 'bd Albaqy).( Qam Bekhrajh Wshhh Washrf 'la Tb't: Mhb Aldyn Alkhtyb).Byrwt: Dar Alm'rfh.

18. Alhlby, Alhsn (1416h). Almqtfa Mn Syrh Almstfa. (T1). (Thqyq: D. Mstfa Aldhby). Alqahrh, Msr: Dar Alhdyth.

19. Abn Hnbl, 'bdallh (1406h). Alsnh. (T1). (Thqyq: D. Mhmd Alqhtany). Aldmam: Dar Abn Alqym.

20. Abn Hzm, 'ly (D.T). Alfsl Fy Almll Walahwa' Walnhl. (D.T).Alqahrh: Mktbh Alkhanjy.

21. Abn Aljwzy, 'bdalrhmn (1395h). Alwfa Bt'ryf Fda'l Almstfa. (D.T).Byrwt: Dar Alm'rfh.

22. Abn Aljwzy, 'bdalrhmn (1412h). Almntzm Fy Tarykh Alamm Walmlwk. (T1). (Thqyq: Hmd 'ta, Mstfa 'ta).Byrwt: Dar Alktb Al'lymh.

23. Altftazany, S'daldyn(1401h). Shrh Almqasd Fy 'Im Alklam. (D.T).Bakstan: Dar Alm'arf Aln'manyh.

24. Abn Tymyh, Ahmd (1406h). Mnhaj Alsnh Alnbwyh Fy Nqd Klam Alshy'h Alqdryh. (T1). (Thqyq: Mhmd Salm).Jam't Alemam Mhmd Bn S'wd Aleslamyh.

25. Abn Tymyh, Ahmd (1416h). Aleyman. (T5). (Thqyq: Mhmd Alalbany).'man, Alardn: Almktb Aleslamy.

26. Abn Tymyh, Ahmd (1422h). Qa'dt Jlylh Fy Altwsl Walwsylh. (T1). (Thqyq: Rby' Almdkhly).'jman: Mktbt Alfrqan.

27. Abn Tymyh, Ahmd (1430h). Shrh Alasbhanyh. (T1). (Thqyq: Mhmd Als'wy).Alryad: Dar Almnhaj.

28. Abn Tymyh, Ahmd (D.T). Alsarm Almslwl 'la Shatm Alrswl. (D.T).(Thqyq: Mhmd 'bd Alhmyd).Almmlkh Al'rbyh Als'wdyh: Alhrs Alwtny Als'wdy.

29. Abn Tymyh, Ahmd (D.T). Mjmw' Alftawa. (D.T). (Thqyq: 'bd Alrhmn Bn Qasm).Almdynh Almnwrh, Almmlkh Al'rbyh Als'wdyh: Mjm' Almlk Fhd Ltba'h Almshf Alshryf.

30. Abn Tymyh, Ahmd (D.T). Mjmw't Alrsa'l Walmsa'l. (D.T). (T'lyq: Alsyd Mhmd Rda). Ljnh Altrath Al'rby. 